\title{
Investigation of C-N Formation Between Catechols and Chitosan for the Formation of a Strong, Novel Adhesive Mimicking Mussel Adhesion
}

\author{
Charlotte Capitain $^{1,3} \cdot$ Sebastian Wagner $^{2} \cdot$ Joana Hummel $^{2} \cdot$ Nils Tippkötter $^{3}$ (D)
}

Received: 25 August 2019 / Accepted: 30 May 2020 / Published online: 18 June 2020

(c) The Author(s) 2020

\begin{abstract}
Mussel-inspired catechol-containing polymers provide a promising basis for developing strong biogenic adhesives. In order to develop such an adhesive, chitosan was functionalized with protocatechuic acid (PCA) via a Michael-type addition. Kinetic models for the $\mathrm{C}-\mathrm{N}$ bond formation between primary amines and catechols via Michael-type addition suggest that the reaction is promoted by a low pKa value of the primary amine used and a neutral or mildly acidic reaction $\mathrm{pH}$. Since the $\mathrm{pKa}$ of chitosan is below 7, spontaneous reactions with catechols were expected, as was confirmed using FT-IR and UV-Vis spectroscopy where spontaneous reactions occurred at $\mathrm{pH} 5$ and 6.5. FT-IR spectroscopy further validated the kinetic model by showing that the spontaneous reaction between chitosan and PCA did not occur at a pH of 1 . While laccases accelerated the $\mathrm{C}-\mathrm{N}$ bond formation between chitosan and catechols, the formation of either PCA-chitosan agglomerates or DHC-chitosan hydrogels was promoted. For a PCA-functionalized chitosan an adhesion strength of $4.56 \pm 0.54 \mathrm{MPa}$ (on sand blasted aluminum surfaces) was achieved. Since the functionalization and curing process uses naturally occurring substances exclusively and is free of toxic chemicals, a novel and sustainable bio-adhesive was developed.
\end{abstract}

Electronic supplementary material The online version of this article (https://doi.org/10.1007/s12649-020-01110-5) contains supplementary material, which is available to authorized users.

Nils Tippkötter

tippkoetter@fh-aachen.de

1 Institute of Bioprocess Engineering, University of Kaiserslautern, Kaiserslautern, Germany

2 NMI Naturwis. Und Medizinisches Institut an Der Universität Tübingen, Reutlingen, Germany

3 Bioprocess Engineering, University of Applied Sciences Aachen, Jülich, Germany 


\section{Graphic Abstract}
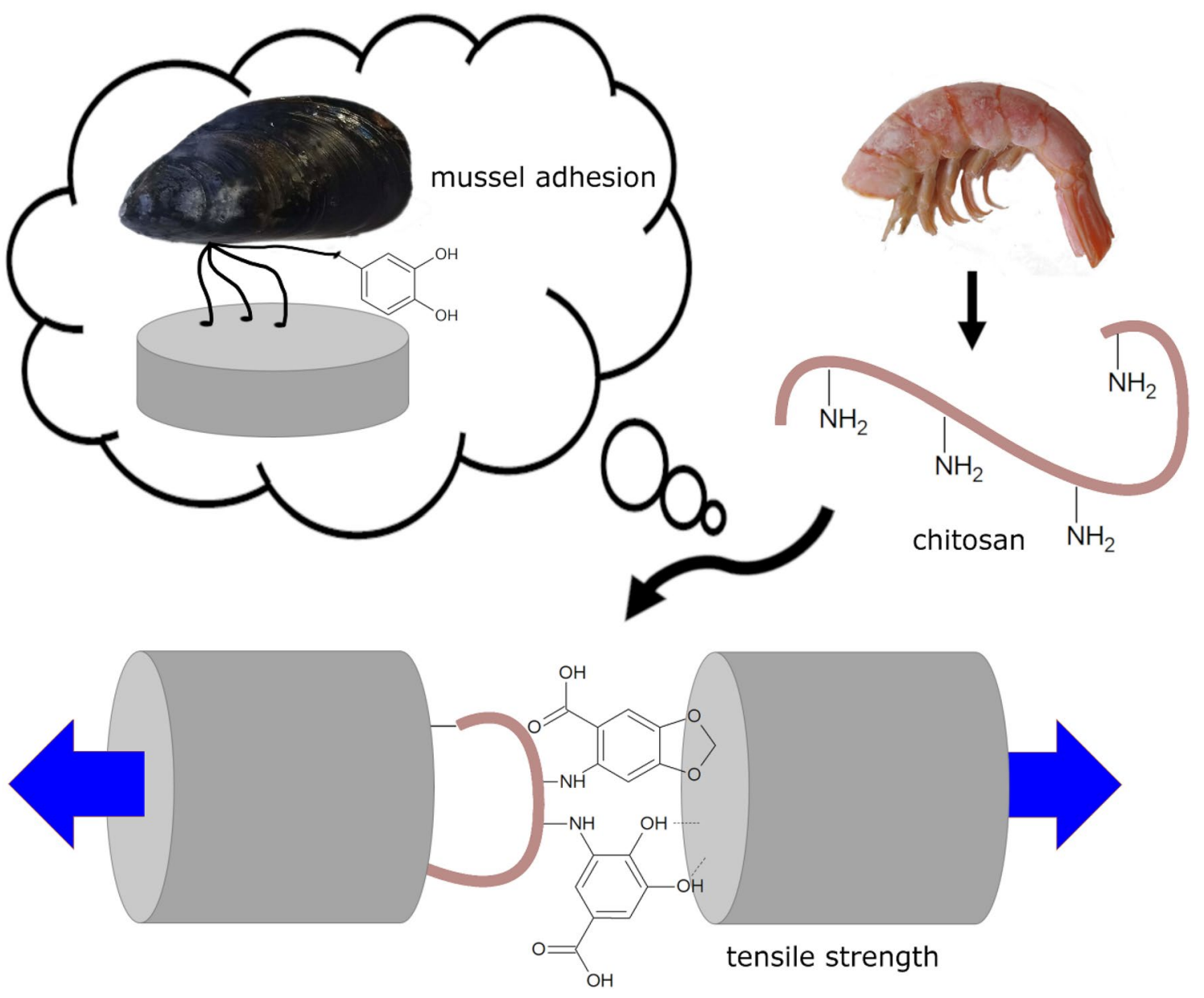

Keywords Adhesive $\cdot$ Chitosan $\cdot$ Renewable resources $\cdot$ Mimicking mussel adhesion $\cdot$ Catechols $\cdot$ Biogenic $\cdot$ Degradable

\section{Statement of Novelty}

A strong and sustainable bio-adhesive was developed by functionalization of chitosan with protocatechuic acid, devoid of toxic chemicals and processes, exclusively using naturally occurring substances.

\section{Introduction}

In molluscs, such as mussels [1], sandcastle worms [2] or squids [3], catechols play an essential role in adhesion under harsh marine conditions [4]. Catechols linked to polymers are not only able to enable strong adhesion to substrate surfaces, they can additionally provide cohesion through bonding with other catechols [5]. In the byssus of the mussel, six mussel foot proteins (mfps) have been identified, each having different amounts of the catechol-containing amino acid L-DOPA (L-3,4-dihydroxyphenylalanine) [6]. It is widely accepted that mfp-3 and mfp-5 play a key role in interfacial adhesion due to their high content of L-DOPA, which was reported to be between $20 \mathrm{~mol} \%$ (mfp-3) and $25 \mathrm{~mol} \%$ (mfp-5) [7]. In order to develop novel biomimetic adhesive materials, several attempts have been made to combine various backbones with catechol groups. For example, Jia et al. (2014) developed a semi-synthetic catechol-containing polyoxetane adhesive polymer which maintained an average lap shear strength of $4.9 \mathrm{MPa}$ [8]. North et al. (2017) synthesised a poly (catechol-styrene) which achieved a strength of up to $3 \mathrm{MPa}$ in an underwater lap shear test [9].

Catechol-containing monomeric molecules are widely found in nature, of which our research concentrated on protocatechuic acid (PCA) and dihydrocaffeic acid (DHC). PCA (3,4-dihydroxybenzoic acid) is a phenolic acid which is commonly found in plums [10], gooseberries, grapes [11], 
olive oil, white wine $[12,13]$ and plants, such as star anise or melissa [14]. It functions as a fungicide [15] in food processes such as cocoa fermentation [16] and tea preparation [17]. Acai oil, which is obtained from the fruit of the Acai palm and known for its antibacterial [18], antioxidant [19], anticancer [20] and anti-inflammatory [21] activities, contains reported PCA concentrations of $630 \pm 36 \mathrm{mg}$ per $\mathrm{kg}$ [22]. PCA's solubility in water is $18.2 \mathrm{mg} \mathrm{mL}^{-1}$ at $14{ }^{\circ} \mathrm{C}$ [23] and the pKa constant lies between 4.26 [24] and 4.48 [25] at $25^{\circ} \mathrm{C}$. PCA has a molar mass of $154.12 \mathrm{~g} \mathrm{~mol}^{-1}$. Its chemical structure is shown in Fig. 1a.

DHC (3-(3,4-dihydrophenyl) propionic acid) has a molar mass of $182.18 \mathrm{~g} \mathrm{~mol}^{-1}$ and acid dissociation constants of $\mathrm{pKa}_{1}=4.56, \mathrm{pKa}_{2}=9.36$ and $\mathrm{pKa}_{3}=11.6$ [26]. Its chemical structure is shown in Fig. 1b. Starting from the amino acid L-tyrosine, caffeic acid is an intermediate product in the proposed ferulic acid biosynthesis pathway [27]. L-Tyrosine is an intermediate product of the shikimate pathway [28, 29] and can be produced recombinantly in Corynebacterium glutamicum [30]. Using the enzyme tyrosine ammonia lyase, L-tyrosine is first converted into 4-coumaric acid [31] which is further converted into caffeic acid and ferulic acid by the enzymes 4-coumarate hydroxylase and caffeic acid methyltransferase [27]. DHC is a degradation product of caffeic acid caused by a bacteria found in the gastrointestinal tract [32]. Antioxidant activity has been reported for both DHC and caffeic acid [33].

Chitin, from which chitosan is derived, belongs to the most abundant organic materials, naturally occurring in the exoskeleton of crustacea, molluscs and as principal fibrillar polymer in certain fungi [34]. With an annual production rate of approximately $10^{11}$ tons [35], chitin and its derivate chitosan are excellent polymers for use as backbones of biogenic adhesives. Chitosan, the deacetylated derivate of chitin, is a non-toxic, microbial resistant and biodegradable polymer [36]. The conversion of chitin to chitosan is possible by enzymatic or chemical deacetylation, resulting in various degrees of deacetylation [37, 38]. Moreover, chitosan consists of glucosamine and $\mathrm{N}$-acetylglucoseamine
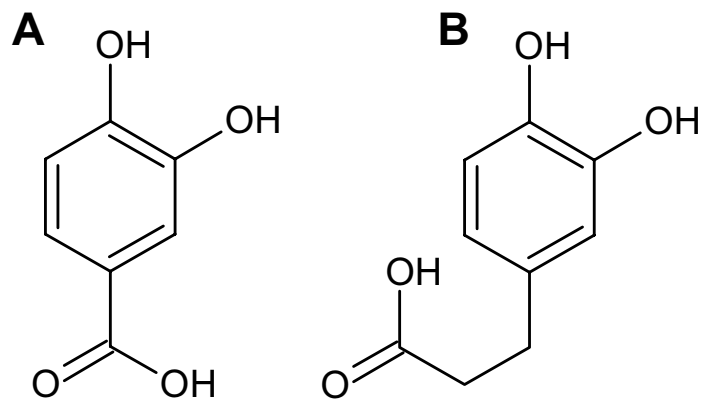

Fig. 1 Chemical structure of a protocatechuic acid and $\mathbf{b}$ dihydrocaffeic acid monomers which are attached to each other via $\beta-(1-4)$ linkages $[39,40]$. Due to their low toxicity, chitin and chitosan are used in various applications such as biomedical materials [35], in the food industry [41], for the treatment of pollutants [42] or for various blends of hydrogels [43, 44]. While chitin is nearly insoluble in water, it was found, that chitosan with a degree of acetylation of less than $50 \mathrm{~mol} \%$ is soluble in water at a pH below $6[45,46]$. Rinaudo et al. (1991) also demonstrated that the concentration of protons needed to solubilize chitosan is at least equal to the concentration of primary amine units involved [45]. The pKa-values of chitosan are reported to be 6.1 [47] 6.2 [48], 6.3 [49] and 6.8 [50]. The pKa value for the monomer of chitosan, D-glucosamine, however, has been reported to be 7.5 [51] and 7.8 [52]. The much lower values obtained for chitosan have been attributed to electrostatic interactions between neighboring $\mathrm{NH}_{3}{ }^{+}$groups [48].

Several chitosan based gels and adhesives have been described in literature. Using $N$-(3-dimethylaminopropyl)$N^{\prime}$-ethylcarbodiimide hydrochloride (ECD), Xu et al. developed a genipin cross-linked catechol-chitosan hydrogel that can be used as a drug delivery system [53]. Zang et al. developed a surgical adhesive containing 3,4-dihydroxyphenylanine acrylamide, poly (ethylene glycol) diacrylate and thiolated chitosan which cures via ultraviolet (UV) irradiation [54]. For an adhesive containing $41.6 \mathrm{~mol} \%$ catechol, a lap shear strength of approximately $1 \mathrm{MPa}$ was reached on gelatin coated glass after UV-curing for $15 \mathrm{~min}$ and an incubation period of $24 \mathrm{~h} \mathrm{[54].} \mathrm{Lee} \mathrm{et} \mathrm{al.} \mathrm{grafted} \mathrm{catechol} \mathrm{groups}$ onto a chitosan backbone using ECD chemistry. By adding $10 \%$ vanadyl ions, a 3D printable bio-ink was developed which was used to produce well-defined grid shapes [55].

Enzymatically catalyzed reactions offer alternatives to the use of toxic chemicals or the requirement of special reaction conditions. The laccase-catalyzed Michael-type addition of catechols and chitosan represent an environmentally friendly alternative to the chemical synthesis strategies. The laccase-catalyzed formation of $\mathrm{C}-\mathrm{N}$ bonds between primary amines (as available in chitosan) and catechols has previously been described [56, 57]. However, laccase-catalyzed reactions often result in more than one product. While the $\mathrm{C}-\mathrm{N}$ bond formation is possible, allowing for the functionalization of a backbone with catechol, often intramolecular bonds are formed in addition to the intermolecular bonds between the same types of molecule. For catechols, both $\mathrm{C}-\mathrm{C}^{\prime}, \mathrm{C}-\mathrm{O}-\mathrm{C}^{\prime}$, as well as various reactions involving the side chains can occur [58-60], resulting in the loss of functionality of the catechol.

Garcia-Carmona et al. (1982) created a kinetic model for the formation of melanin from L-DOPA, which plays a key role in interfacial adhesion of mussels [5, 57]. Based on the mechanism postulated by Lerner et al. (1950), the conversion of L-DOPA to dopachrome is described as an 
enzymatic-chemical-chemical mechanism $\left(\mathrm{E}_{\mathrm{z}} \mathrm{CC}\right)$. In a first step, the enzyme catalyzes the conversion of L-DOPA to dopaquinone- $\mathrm{H}^{+}$[61]. The second step involves the deprotonation of the amine group dopaquinone- $\mathrm{H}^{+}$, forming dopaquinone, and the ring closure forming leukodopachrome. In the third step, dopachrome is formed, either enzymatically catalyzed or as a result of the redox reaction involving the reverse reaction of dopaquinone- $\mathrm{H}^{+}$to L-DOPA. Dopachrome reacts further to 5,6-dihydroxyindole, which eventually forms melanin. For the conversion rate of dopaquinone- $\mathrm{H}^{+}$to leukodopachrome, an equation (Eq. 1) was derived, where $\mathrm{k}_{1}$ is the specific rate constant of the deprotonation step, $\mathrm{K}_{\mathrm{a}}$ is the ionization constant of the amino group of dopaquinone- $\mathrm{H}^{+}$and $\mathrm{k}_{\mathrm{c}}$ is the specific rate constant for the ring closure (intramolecular 1,4 addition of Michael). The $\mathrm{K}_{\mathrm{a}}$ value of L-DOPA is $1.91 \cdot 10^{-9} \mathrm{M}$. The specific constant $\mathrm{k}$ increases with temperature and $\mathrm{pH}$ [57].

$\frac{1}{k}=\frac{1}{K_{a} \cdot k_{c}}\left[\mathrm{H}^{+}\right]+\frac{1}{k_{1}}=\frac{1}{k_{c}} \cdot 10^{\left(-\mathrm{pH}+p K_{a}\right)}+\frac{1}{k_{1}}$

The study of laccase-, or of a tyrosinase-catalyzed formation of a $\mathrm{C}-\mathrm{N}$ bond between a catechol ring and a primary amine suggest that the pKa value of the primary amine has a significant impact on the reaction rate [56, 57]. For aromatic amines with a pKa value of 5 to 6 , the quinone-aromatic amine adducts form even at an acidic $\mathrm{pH}[46,62]$. However, for catechol-amines used as coating material for nanofiltration membranes, it was shown that catechol-m-phenylenediamine aggregates grow much faster than catechol-piperazine aggregates [63]. According to the authors, secondary amines are less likely to react via a Michael-type addition due to intermolecular pi-pi interactions.

In nature, insect cuticles contain catechol-histidine crosslinked proteins, which are linked via the aromatic amines of histidine (pKa of imidazole groups $=5,97$ [26]) [64, 65]. For the sclerotization of insect cuticles via histidine, however, it has been shown that besides the catechol-ring, the side chain of the catecholamines are also used for cross-linking, which suggests that more sophisticated mechanisms are taking place $[66,67]$.

The attempt to transfer catechols or derivates, such as phenolic compounds, onto lignin has been previously achieved in order to create new adhesives. Peshkova et al. (2003) modified chitosan with phenolic compounds using laccases. Maple veneer strips that were hot-pressed $\left(105^{\circ} \mathrm{C}\right.$, $0.7 \mathrm{MPa}$ for $5 \mathrm{~min}$ ) with chitosan-phenolic-laccase systems containing 3,5-dimethoxy-4-hydroxycinnamic acid or caffeic acid, achieved shear strengths of $2.75 \mathrm{MPa}$ [68]. After the treatment with laccases, phenolic compounds form radicals that undergo polymerisation reactions with the veneer's lignin, resulting in adhesion. Using 3,4-dimethoxy4-hydroxycinnamic acid, a water stable adhesion strength of
$2 \mathrm{MPa}$ was achieved. However, while the results were promising, it is doubtful that the process is indeed mimicking mussel adhesion. Laccase treatment leads to oxidized phenolic compounds and catechols. Hence, after intense laccase treatment, catechols are expected to be incapable of adhering to metallic surfaces (which mussels are capable of doing).

The goal of this work is the development of a novel and sustainably sourced chitosan adhesive, which mimics a mussel's adhesion mechanism. By grafting catechols (PCA and DHC) onto a chitosan backbone, via spontaneous and laccase-catalyzed Michael-type addition, between the catechol monomers and the primary amines of chitosan, a process is investigated with the intention of avoiding the use of toxic chemicals and the requirement of special reaction conditions.

\section{Experimental Section}

\section{Chemicals}

Low molecular weight chitosan (poly(D-glucosamine), Lot: STBH6262) with a deacetylation degree of 75-85 mol\% was obtained from Sigma Aldrich, MO, United States. The glucosamine (molar mass: $179.17 \mathrm{~g} \mathrm{~mol}^{-1}$ ) and $N$-acetylglucoseamine (molar mass $221.21 \mathrm{~g} \mathrm{~mol}^{-1}$ ) monomers are B-( $1 \rightarrow 4)$-linked. The average molar mass can be calculated to $80 \%(170.17-18.02) \mathrm{g} \mathrm{mol}^{-1}+20 \%(221.21-18.02)$ $\mathrm{g} \mathrm{mol}^{-1}=162.36 \mathrm{~g} \mathrm{~mol}^{-1}$. This would result in an estimated $4.93 \mathrm{mmol}$ of primary amines per gram of chitosan (at $80 \%$ deacetylation). 3,4-Dihydroxybenzoic acid (PCA, 97\%, LOT:10,180,353) and 3-(3,4-dihydroxyphenyl) propionic acid (DHC, 98\%, LOT: 10,194,476) were purchased from Alfa Aesar, MA, United States.

\section{Cultivation and Purification of Laccases from C. unicolor}

The laccase producing white rot fungus $C$. unicolor (PM1070798) obtained from HAMBI Culture Collection, Helsinki, Finland (Hambi No. FBCC 387) was cultivated in a $500 \mathrm{~mL}$ baffled flask at $28{ }^{\circ} \mathrm{C}$ in modified Kirk medium $[69,70]$, containing $13 \mathrm{~g} \mathrm{~L}^{-1}$ of glucose. After three weeks of incubation, the liquid broth was separated from the fungus via decanting, and purified using a laboratory crossflow cassette Vivaflow $50 \mathrm{R}$ with a molecular weight cut off (MWCO) of 30.000 and a polyethersulfone membrane (Fa. Satorius, Göttingen). The medium components were washed out using a dialysis set up. Afterwards, the broth was concentrated by a factor of 10 . In order to prevent growth, the concentrate was filtered through a $0.2 \mu \mathrm{m}$ nylon filter and stored at $4{ }^{\circ} \mathrm{C}$ for several weeks. The activity was measured 
using colorimetric assay with syringaldazine (see "Enzyme Assay").

\section{Enzyme Assay}

The laccase activity was measured using a colorimetric assay with $10 \mu \mathrm{M}$ syringaldazine (Fa. Sigma Aldrich, MO, United States; LOT: 042K3735) as substrate at a wavelength of $530 \mathrm{~nm}$ using an Agilent Cary $50 \mathrm{UV}-\mathrm{Vis}$ spectrometer (Agilent Technologies, United States) and an extinction coefficient of $\varepsilon_{530}=65 \mathrm{mM} \mathrm{cm}^{-1}$ [71, 72]. One unit of enzyme activity (U) was defined as the amount of enzyme that converts $1 \mu \mathrm{mol}$ of syringaldazine per minute at $25^{\circ} \mathrm{C}$. Each measurement was performed in triplicates.

\section{Enzyme Characterization}

Purification degree and molecular weight (MW) of the laccase isoforms was determined by sodium dodecyl sulfate-polyacrylamide gel electrophoresis (SDS-PAGE, 5\% stacking gel and $12 \%$ running gel), using an unstained protein marker (Pierce, Fa. Thermo Fisher, United State) as reference. After electrophoresis, the gel was stained to visualize protein bands using Coomassie R/G-250 (Fa. Sigma Aldrich, MO, United States). The logarithmic molar mass ( $\log M W)$ of the reference proteins over the relative mobility $\left(\mathrm{R}_{\mathrm{f}}\right)$ was modeled linearly, resulting in the following equation: $\log (M W[\mathrm{kDa}])=0.147 \mathrm{~cm}^{-1} \cdot R_{f}[\mathrm{~cm}]+1.110$. The coefficient of determination was 0.995 . The protein concentration was determined using the Bradford method with the Pierce Coomassie Protein Assay Kit (Fa. Thermo Fisher Scientific, United States) and a serum albumin as a standard.

\section{The pH Optimum for Laccase-Catalyzed PCA Conversion}

The optimum $\mathrm{pH}$ for enzyme activity is highly dependent on the substrate used [69]. In order to determine the optimum $\mathrm{pH}$ for the conversion of PCA, $10 \mathrm{mM}$ of PCA were dissolved in $0.1 \mathrm{M}$ McIlvaine buffer at $\mathrm{pH} 4.5,5.5,6.5,7.5$ and 8.5 . The relative enzyme activity was measured with a colorimetric assay at $400 \mathrm{~nm}$ using a laccase solution containing 0.5\% PCA-solution.

\section{High-Performance Liquid Chromatography (HPLC) analysis}

A Waters HPLC-System (Alliance 2695) was used in combination with a Waters 2996 photodiode array detector (PDA) between 190 and $700 \mathrm{~nm}$ (Fa. Waters, Milford, United States). A reversed phase $\mathrm{C}_{18}$ column (Eurospher II, 100-5 $\mathrm{C} 18$, Fa. Knauer, Berlin, Germany) was used at $30^{\circ} \mathrm{C}$ with a flow of $0.5 \mathrm{~mL} \mathrm{~min}^{-1}$ (resulting in approx. 190 bar pressure). First, the column was equilibrated for 15 min with 80 vol\% buffer A ( $0.1 \mathrm{vol} \%$ formic acid in de-ionized water) and 20 vol\% buffer B ( 0.1 vol\% formic acid in methanol). Following, the sample was injected into the HPLC. After 10 min of isocratic flow, the gradient towards $100 \mathrm{vol} \%$ buffer B started. After $20 \mathrm{~min}, 100 \mathrm{vol} \%$ buffer B was reached and isocratic flow was continued for $5 \mathrm{~min}$.

The investigation of enzyme-mediated reactions and spontaneous reactions were done in $2 \mathrm{~mL}$ reaction vessels (final concentration $20 \mathrm{mM}, 1 \mathrm{~mL}$ ) at $28.5^{\circ} \mathrm{C}$, under aerobe reaction conditions and in the dark. The enzyme mediated reactions were conducted for $60 \mathrm{~min}$, while non-enzymatic reactions for $24 \mathrm{~h}$.

\section{Electrospray lonization-Mass spectroscopy (ESI-MS)}

The HPLC unit was coupled with an electrospray ionization (ESI) Quattro LC (Fa. Waters Micromass, Milford, United States), resulting in an increased retention time of approximately $0.5 \mathrm{~min}$. The molar mass was detected using electrospray ionization (ESI) under a nitrogen flow of 800 $\mathrm{L} \mathrm{h}^{-1}$. For positive $(\mathrm{ESI}+)$ as well as negative ionization (ESI-), the source block temperature was $100{ }^{\circ} \mathrm{C}$, the desolvation temperature $450{ }^{\circ} \mathrm{C}$, the capillary potential $3.5 \mathrm{~V}$ and the cone voltage of $20 \mathrm{~V}$. Fragments between 100 and $1000 \mathrm{~g} \mathrm{~mol}^{-1}$ were analyzed.

\section{Spectroscopy}

\section{Determination of PCA Concentration in Liquid Media}

In an aqueous solution, PCA has two distinct absorption maxima at wavelengths of $252 \mathrm{~nm}$ and $290 \mathrm{~nm}$. Using an Agilent Cary 50 UV-Vis spectrometer, the extinction coefficient was determined to be $0.376 \mathrm{~L} \mathrm{~mol}^{-1} \mathrm{~cm}^{-1}$ (at $252 \mathrm{~nm}$ ) and $0.173 \mathrm{~L} \mathrm{~mol}^{-1} \mathrm{~cm}^{-1}$ (at $290 \mathrm{~nm}$ ).

In order to determine the $\mathrm{pH}$-dependant absorption changes of PCA on chitosan, a solution of $10 \mathrm{~g} \mathrm{~L}^{-1}$ chitosan was mixed with PCA (solid) to a final molar concentration of $25 \mathrm{~mol} \%, 50 \mathrm{~mol} \%$ and $100 \mathrm{~mol} \%$ with respect to chitosan's available amine groups (see "Chemicals" for details). For each molar concentration of PCA, a solution with a final reaction $\mathrm{pH}$ of 5 and 6.5 were prepared. Samples were taken after $15 \mathrm{~min}, 3 \mathrm{~h}$ and $18 \mathrm{~h}$ of incubation; the chitosan was then removed via centrifugation at $16,500 \times g$ (Centrifuge 5418, Eppendorf Wesseling-Berzdorf, Germany). The supernatant was diluted in de-ionized water and the PCA concentration was measured with $\mathrm{UV}-\mathrm{Vis}$ spectroscopy at a wavelength of $400 \mathrm{~nm}$.

\section{Turbidity Measurements}

A $10 \mathrm{~g} \mathrm{~L}^{-1}$ solution of chitosan in de-ionized water was prepared and left to settle, until a pH of 8 was reached (after 
approximately $15 \mathrm{~min})$. DHC at a molar concentration of $25 \mathrm{~mol} \%$ or PCA at molar concentrations of either $25 \mathrm{~mol} \%$ or $50 \mathrm{~mol} \%$ (with respect to the chitosan's available amine groups) were stirred in and the $\mathrm{pH}$ was gradually lowered using $\mathrm{HCl}(32 \mathrm{vol} \%)$. Samples were taken and the turbidity was determined at a wavelength of $680 \mathrm{~nm}$ using an Agilent Cary 50 UV-Vis spectrometer (Agilent Technologies, United States). As a control, no DHC or PCA was added. Each measurement was performed in triplicates.

\section{Viscometry Measurements}

The kinematic viscosity was measured using an Ubbelohde viscometer (Fa. SI Analytics $\mathrm{GmbH}$, Mainz) at $30{ }^{\circ} \mathrm{C}$. The device constant was determined by the producer to $\mathrm{K}=0.3147 \mathrm{~mm}^{2} \mathrm{~s}^{-2}$ (according DIN 55 350; capillary number: 501 23/IIc).

\section{Particle Size Characterization}

\section{Formation of Catechol-Chitosan Agglomerates}

For the investigation of the effect of enzymes, a solution of $10 \mathrm{~g} \mathrm{~L}^{-1}$ chitosan in $10 \mathrm{vol} \%$ McIlvaine buffer was prepared and a $\mathrm{pH}$ of 5 was adjusted before adding PCA at a concentration of $100 \mathrm{~mol} \%$ (in respect to chitosan's available amine groups). To the reaction mixture, 0.1 vol\% enzyme was added. As control, a mixture of chitosan and PCA without enzyme was prepared. Samples were taken after $90 \mathrm{~min}$ of incubation and $24 \mathrm{~h}$ of incubation at $28^{\circ} \mathrm{C}$. A volume of $1 \mathrm{~mL}$ of reaction mixture was centrifuged in a $2 \mathrm{~mL}$ reaction vessel at 16,500 $\times g$ (Centrifuge 5418, Eppendorf WesselingBerzdorf, Germany). The supernatant was discarded and the pellet was washed using de-ionized water. The pellet was stored at $-20{ }^{\circ} \mathrm{C}$ for further use. In order to characterize the particle size of the catechol-chitosan agglomerates after $90 \mathrm{~min}$ or $24 \mathrm{~h}$ of enzyme treatment, the frozen pellet was resuspended in de-ionized water.

\section{Particle Size Analysis}

The particle size characterization was conducted using a particle size analyser (LUMiReader, Fa. LUM GmbH, Berlin). The extinction profile of the transmitted light through the width of the sample was measured over time. The velocity distribution of the separating particles was calculated via the software SEPView. In order to be able to estimate the particle size from the velocity measurements, the refractive index, the viscosity and density of the medium, as well as the particle density and refractive index of the particle were needed. Measurements were conducted at $30^{\circ} \mathrm{C}$ using de-ionized water as the continuous phase. The material properties of water were used according to the programs specifications: viscosity $\left(30{ }^{\circ} \mathrm{C}\right)=0.7992 \mathrm{mPa}$ s; density $\left(30{ }^{\circ} \mathrm{C}\right)=995.9441 \mathrm{~kg} \mathrm{~m}^{-3}$ [73], RPRI $(630 \mathrm{~nm})=1.3308$ and RPRI $(870 \mathrm{~nm})=1.3259$ [74].

The refractive index (RI) for chitosan was previously reported to be between 0.166 and $0.180 \mathrm{~cm}^{3} \mathrm{~g}^{-1}$ (measured at $546 \mathrm{~nm}$ ) [48]. Here, a RI of $0.166 \mathrm{~cm}^{3} \mathrm{~g}^{-1}$ and a particle density of $1500 \mathrm{~kg} \mathrm{~m}^{-3}$ was used.

The particle size analysis was validated using an optical microscope (Nikon Eclipse Ni). The particle size was initially determined for the control reaction after $90 \mathrm{~min}$ and the enzyme catalyzed reaction after $90 \mathrm{~min}$ and $24 \mathrm{~h}$ using the software NIS-Elements D.

\section{Mid-infrared Analysis}

Mid-infrared spectra of spontaneous reaction of catechols with chitosan were obtained using an FT-ATR mid-infrared spectrometer 'Spectrum 100' (Fa. Perkin Elmer) over the range of $4000 \mathrm{~cm}^{-1}$ to $650 \mathrm{~cm}^{-1}$. First, a chitosan solution of $100 \mathrm{~g} \mathrm{~L}^{-1}$ was prepared in de-ionized water and the $\mathrm{pH}$ was adjusted using concentrated $\mathrm{HCl}$ (32 vol\%). Second, the model compounds, DHC or PCA, were added to a concentration of $30 \mathrm{~mol} \%$ in respect to chitosan's available amine groups. The solution was measured after $\mathrm{t} 0=0 \mathrm{~min}$, $\mathrm{t} 1=30 \mathrm{~min}$ and $\mathrm{t} 2=3 \mathrm{~h}$. Each sample was measured in triplicates. De-ionized water was used as background media.

\section{Preparation of Adhesive and Measurement of Tensile Strength}

The adhesive was prepared as follows. $3 \mathrm{~g}$ of chitosan were dissolved in $25 \mathrm{~mL}$ of de-ionized water. Following, a solution containing of $900 \mu$ l concentrated $\mathrm{HCl}$ (32 vol\%) and $5 \mathrm{~mL}$ of de-ionized water were added to lower the $\mathrm{pH}$ from $\sim 9$ to $\sim 5$. This $\mathrm{pH}$ shift was necessary in order to avoid oxidation of the catechol group and to shift the $\mathrm{NH}_{2}$ groups towards $\mathrm{NH}_{3}{ }^{+}$. Due to the $\mathrm{pH}$-shift, the chitosan formed a gel, which was advantageous for the application on the adhesion surface (no running off), but limited the maximum concentration of the adhesive Thereafter, $701 \mathrm{mg}$ of PCA were added and left to incubate for $30 \mathrm{~min}$. The covalent bond between chitosan and PCA formed during the $72 \mathrm{~h}$ curing time, without the use of a catalysts, via spontaneous reaction.

The adhesion was tested with a tensile test according to DIN EN 15870 with aluminium cylinders with a diameter of $20 \mathrm{~mm}$. Therefore, the test surfaces were prepared with an abrasive pad and cleaned using first de-ionized water then acetone. One surface was covered with adhesive (approximately $1.5 \mathrm{~mm}$ high) and gently placed on top of the other. 
Unless otherwise noted, the curing was conducted at $28{ }^{\circ} \mathrm{C}$ for $72 \mathrm{~h}$.

In order to test the influence of $\mathrm{pH}, \mathrm{NaOH}$ was mixed in prior to PCA. The $\mathrm{pH}$ was measured after PCA addition using a $\mathrm{pH}$ meter.

Organosolv (OS)-lignin used as filler materials in adhesion experiments was provided by the Fraunhofer Center for Chemical-Biotechnological Processes CBP in Leuna, Germany. The OS-lignin was extracted from beech wood using ethanol as a solvent (KO74).

\section{Results and Discussion}

In this work, we introduce a novel catechol adhesive that consists of a chitosan backbone with a catechol group, mimicking the adhesion of mussels. First, enzymatically catalyzed model reactions between catechols and primary amines are investigated. Second, chitosan is functionalized and the adhesion strength was measured. Third, further optimization towards higher water resistance is conducted.

\section{Enzyme Production and Characterization}

After cultivation of $C$. unicolor and enzyme purification, the purification success was evaluated using an SDS page (Fig. 2). Three protein bands were identified with a size of

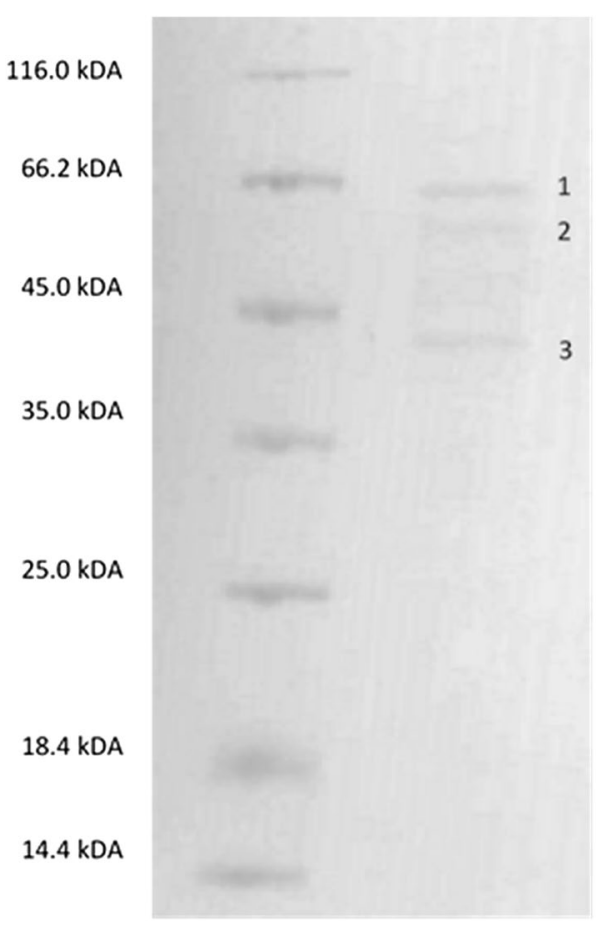

Fig. 2 SDS-page of purified laccase from C. unicolor. Left lane: Pierce protein marker, right lane: purified protein
(1) $62.4 \mathrm{kDa}$, (2) $57.2 \mathrm{kDa}$ and (3) $45.0 \mathrm{kDa}$. While protein 1 and 3 seem to have a stronger intensity, protein 1 and 2 are likely attributed to the two isoforms of laccase (Lacc I: $64 \mathrm{kDa}$ and Lacc II: $57 \mathrm{kDa}$ ) previously described by Michniewicz et al. (2006) [69]. Purified Lacc II was shown to exhibit higher activity towards 2,2'-azino-bis(3-ethylthiazoline-6-sulfonate) (ABTS), 2,6-dimethoxyphenol and syringaldazine at higher $\mathrm{pH}$ values compared to Lacc I, whose pH optimum was shifted 1 to $2 \mathrm{pH}$ units towards more acidic conditions [69]. A crude enzyme mix of both laccases was therefore expected to show a broad $\mathrm{pH}$ optimum.

The protein content was determined to be $0.11 \mathrm{~g}$ $\mathrm{L}^{-1} \pm 0.02 \mathrm{~g} \mathrm{~L}^{-1}$. The specific enzyme activity at $\mathrm{pH}$ 5.0 and $\mathrm{pH} 6.5$ was $47.1 \mathrm{U} \mathrm{mg}^{-1} \pm 0.2 \mathrm{U} \mathrm{mg}^{-1}$ and 53.8 $\mathrm{U} \mathrm{mg}^{-1} \pm 0.2 \mathrm{U} \mathrm{mg}^{-1}(10 \mu \mathrm{M}$ syringaldazine at $530 \mathrm{~nm}$ and $\left.25^{\circ} \mathrm{C}\right)$, respectively.

In preparation for the catechol-chitosan, the $\mathrm{pH}$ optimum of the laccase-catalyzed conversion of PCA was determined. For the conversion of PCA to 1,2-benzoquinone-4-carboxylic acid (BQA) a maximal conversion rate was detected for a pH of 5.5 (Fig. 3). Since the extinction coefficient was not known, only the relative enzyme activity was measured by comparing the absorption gain at $400 \mathrm{~nm}$. For PCA and syringaldazine, a broad $\mathrm{pH}$ optimum was shown, suggesting the presence of Lacc I and Lacc II.

\section{Laccase Catalyzed Reaction with Model Compounds}

The laccase-catalyzed formation of a $\mathrm{C}-\mathrm{N}$ bond between a primary amine and a catechol was investigated for the

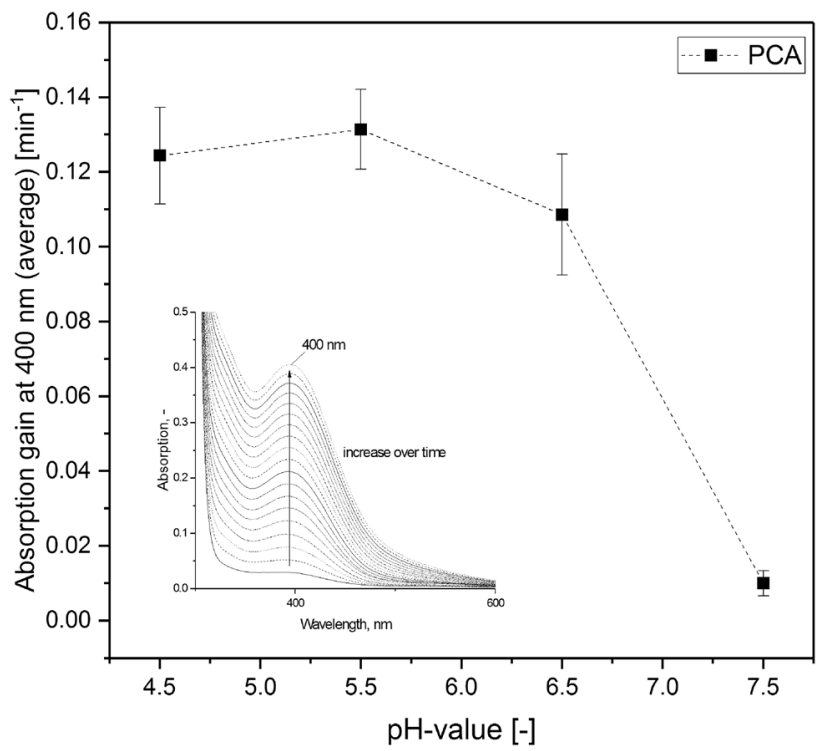

Fig. 3 pH-optimum of the laccase-catalyzed conversion of PCA. The subgraph shows an example spectrum for the formation of BQA over time in $15 \mathrm{~s}$ increments. The reaction progress was measured at $400 \mathrm{~nm}$ 
development of a catechol-chitosan adhesive. In order to investigate the desired $\mathrm{C}-\mathrm{N}$ bond formation between catechols and primary amines, the model compounds DHC and PCA as catechol groups and $N$-acetyl diaminopentane (NAcDAP) as primary amine were used. For the purpose of differentiating between enzyme mediated reactions from spontaneous reactions, single component reactions (without enzyme) were performed. To identify intermolecular bonds between different molecule types, HPLC-MS analysis of enzyme-catalyzed conversions of the single components were conducted and used as comparison. Hence, the reaction mixtures were analysed prior to and after enzyme incubation, using HPLC-MS analysis. Table 1 gives an overview of the possible molecule structures after the enzymatic reaction. Detailed mass spectrometric data was provided as supplement material.

The mass spectroscopy coupled behind the UV-Vis detector led to increased retention times of approximated $0.5 \mathrm{~min}$. The UV-Vis and mass spectroscopy results were presented in pairs with the retention time from the mass spectrometer presented in parenthesis. For NAcDAP, a retention time of 2.51-2.93 $\mathrm{min}$ (no mass spectroscopy data recorded), as well as a minor peak at $7.36 \mathrm{~min}(7.74 \mathrm{~min})$ with a mass of $144 \mathrm{~g} \mathrm{~mol}^{-1}$ (ESI+: 145 , no ESI-) was found. The enzyme incubation did not notably change the spectra. Hence, it was concluded that NAcDAP was not a substrate for the enzyme.

For the substrate PCA, a peak was found with a retention time of $8.59 \mathrm{~min}(8.97 \mathrm{~min})$ and a mass of $154 \mathrm{~g} \mathrm{~mol}^{-1}$

Table 1 Proposed chemical structure of PCA and DHC and their enzyme catalyzed intermediate products and dimers with NAcDAP. The molar mass of each structure is provided together with the mz-ratios, which were detected using HPLC-MS analysis

Catechol
Proposed chemical structure of
substrate prior to enzyme
treatment
Quinone
Proposed chemical structure
cleavage product from mass
spectrometer analysis

Dimer of catechol and NAcDAP

Proposed chemical structure after dimer formation and cleavage product from mass spectrometer analysis

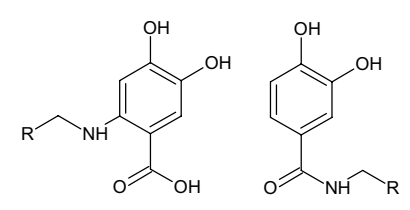

$296 \mathrm{~g} \mathrm{~mol}^{-1}$ and $280 \mathrm{~g} \mathrm{~mol}^{-1}$

(ESI-: 295; ESI+: 281)<smiles>O=C(O)CCC1=CC(=O)C(=O)C=C1CCP</smiles>

$322 \mathrm{~g} \mathrm{~mol}^{-1}$ and $323 \mathrm{~g} \mathrm{~mol}^{-1}$<smiles>[R]=[Fe]</smiles> 
(ESI-: 153, ESI+: 137). The observed delta of $18 \mathrm{~g} \mathrm{~mol}^{-1}$ in the ESI+ spectra results may have resulted from the cleavage of the OH-group (Table 1 shows a possible structure). After 60 min of PCA incubation with the enzyme, a new peak at $10.56 \mathrm{~min}$ (10.95 min) appeared with a mass of $140 \mathrm{~g} \mathrm{~mol}^{-1}$ or $168 \mathrm{~g} \mathrm{~mol}^{-1}$ (ESI+: 141 and 169, no ESI-), the expected quinone structure of $152 \mathrm{~g} \mathrm{~mol}^{-1}$ was only observed in small quantities. Consequently, it was concluded that the quinone reacts further, forming $\mathrm{C}-\mathrm{C}^{\prime}$ or $\mathrm{C}-\mathrm{O}-\mathrm{C}^{\prime}$ bonds that cleave into fragments of $140 \mathrm{~g} \mathrm{~mol}^{-1}$ or $168 \mathrm{~g} \mathrm{~mol}^{-1}$ during MS analysis. For the enzyme catalyzed reaction of PCA with NAcDAP at $\mathrm{pH} 5$, a strong peak was found at $17.77 \mathrm{~min}(18.13 \mathrm{~min})$ with a mass of either $280 \mathrm{~g} \mathrm{~mol}^{-1}$ or $296 \mathrm{~g} \mathrm{~mol}^{-1}$ (ESI+: 281, ESI-:295). Both structures corresponded well to $\mathrm{C}-\mathrm{N}$ connected dimers of PCA and NAcDAP (possible structures are given in Table 1). While structure $1\left(296 \mathrm{~g} \mathrm{~mol}^{-1}\right)$ corresponded well to an aromatic secondary amine, structure $2\left(280 \mathrm{~g} \mathrm{~mol}^{-1}\right)$ corresponded better to an amide bond. Literature suggested the formation of an aromatic secondary amine [56].

After $24 \mathrm{~h}$ of non-enzyme catalyzed incubation of PCA with NAcDAP at both $\mathrm{pH} 5$ and $\mathrm{pH}$ 8, no corresponding dimer peak was detected. Accordingly, no spontaneous reaction was detected between PCA and NAcDAP.

For the substrate DHC, a peak at $14.6 \mathrm{~min}(15.4 \mathrm{~min})$ with a mass of $182 \mathrm{~g} \mathrm{~mol}^{-1}$ (ESI-:181, ESI+: 165) was detected. After enzymatic incubation, several new peaks were detected: (1) $13.58 \mathrm{~min}$ (13.99 min) with a mass of $180 \mathrm{~g} \mathrm{~mol}^{-1}$ (ESI-: 179, ESI+: 181); (2) at $20.04 \mathrm{~min}$ (20.40 $\mathrm{min}$ ) and (3) $21.34 \mathrm{~min}$ (21.75 min). For peak 2 and 3 various masses were found, which indicate multiple product formation. Identification was not possible via mass spectroscopy. For the enzyme catalyzed reaction of NAcDAP and DHC, again, several new peaks were observed: (1) $12.16 \mathrm{~min}$ (12.47 min) with a mass of $180 \mathrm{~g} \mathrm{~mol}^{-1}$, (2) $16.23 \mathrm{~min}$ $\left(16.61 \mathrm{~min}\right.$ ) and a mass of 322 and $323 \mathrm{~g} \mathrm{~mol}^{-1}$ (ESI+: 323, 324, ESI-:321, 322) and (3) $20.44 \mathrm{~min}$ (20.74 min) (no plausible mass detected). Peak 2 likely corresponded to the proposed dimer between DHC and NAcDAP (see Table 1). In contrast to the non-enzymatic incubation of PCA with NAcDAP, for DHC a dimer peak was found which seems to form spontaneously. The mass of 322 or $323 \mathrm{~g} \mathrm{~mol}^{-1}$ was also found for the non-enzymatic incubation of DHC with NAcDAP at a pH above 5. At pH 5.8, 6.2 and 8.2 increasing amounts of the dimer were detected.

For the enzyme-catalyzed reaction of PCA with NAcDAP, two possible dimer structures were proposed. Either an aromatic amine with a molar mass of $296 \mathrm{~g} \mathrm{~mol}^{-1}$ or an amide with a molar mass of $280 \mathrm{~g} \mathrm{~mol}^{-1}$. Both structures suggest a functional catechol group. However, the mass of 322 or $323 \mathrm{~g} \mathrm{~mol}^{-1}$ detected for DHC with NAcDAP, corresponded better with the oxidized form of the catechol, than with the catechol itself.
Even though PCA and DHC have similar compositions (both are catechols with a carboxylic side chain) the product formation was quite different. While PCA only seemed to form $\mathrm{C}-\mathrm{N}$ bonds to NAcDAP after enzyme-catalyzed reaction, for DHC also spontaneous formation of dimers were observed. The catalysis with enzyme led to a broad spectrum of products, which was unfavourable for a specific reaction. DHC was more reactive and less stable. Since the non-oxidized form of the catechol was necessary for the formation of a strong catechol adhesive, DHC appeared to be less suitable as a catechol donor. Therefore, it was concluded that PCA was a more favourable catechol donor for chitosan functionalization.

\section{Influence of the pH Value and the Primary Amines' pKa for C-N Bond Formation to Catechols}

The HPLC-MS analysis of C-N bond formation between the model compounds DHC, PCA as catechol groups and NAcDAP as primary amine has shown, that the choice of catechol influences the reaction outcome. While DHC was more reactive and able to form spontaneous $\mathrm{C}-\mathrm{N}$ bonds to NAcDAP, it also produced a large amount of side products. In contrast to DHC, PCA was only able to form $\mathrm{C}-\mathrm{N}$ bonds to NAcDAP, after enzymatic activation. Next to the origin of the catechol donor, the primary amine used had a major impact on the reaction rate. Based on the model proposed by Garcia-Carmona et al. (1982) (see "Introduction"), in this work an adjusted model for the formation of intermolecular $\mathrm{C}-\mathrm{N}$ bonds was created [57].

The $\mathrm{pH}$ of the reaction mixture and the $\mathrm{pKa}$ of the primary amine played a key role in the formation of intramolecular $\mathrm{C}-\mathrm{N}$ bonds [57]. Due to the similar molecular structure, it was assumed that $\mathrm{pH}$ and $\mathrm{pKa}$ also play a key role in intermolecular $\mathrm{C}-\mathrm{N}$ bond formation between primary amines and catechols. The adjusted model for the intermolecular $\mathrm{C}-\mathrm{N}$ bond formation is shown in Fig. 4. The formation of quinones from the catechol was catalyzed by the enzyme tyrosinase or laccase as well as due to auto-oxidation. Kramer et al. (2001) proposed, that laccases form o-quinones and p-qinone methides [66]. The quinone methides form zwitterionic valence bond structures explain the formation of aromatic amines as well as amides.

The rate $\mathrm{k}_{\mathrm{c}}$ is the specific rate constant for the intermolecular formation of an aromatic, secondary amine between a catechol and an amine. From Eq. 1 it was established, that a high $\mathrm{pH}$ of the reaction medium and a low $\mathrm{pK}_{\mathrm{a}}$ of the primary amine is favourable for the formation of $\mathrm{C}-\mathrm{N}$ bonds. For reactions, where the $\mathrm{pH}$ value is smaller than the $\mathrm{pK}_{\mathrm{a}}$ value of the primary amine, $\frac{1}{k}$ approaches infinity; hence the reaction rate is very slow. For reaction mixtures with a $\mathrm{pH}$ equal to the $\mathrm{pK}_{\mathrm{a}}$ of the primary amine, the term $\frac{1}{K_{a} \cdot k_{c}}\left[\mathrm{H}^{+}\right]$ 


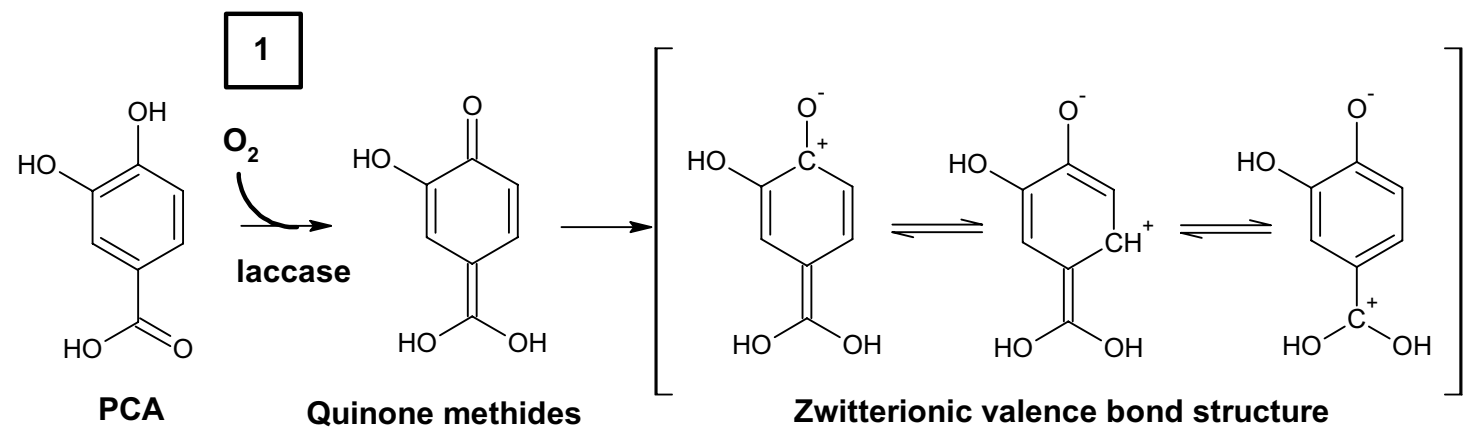

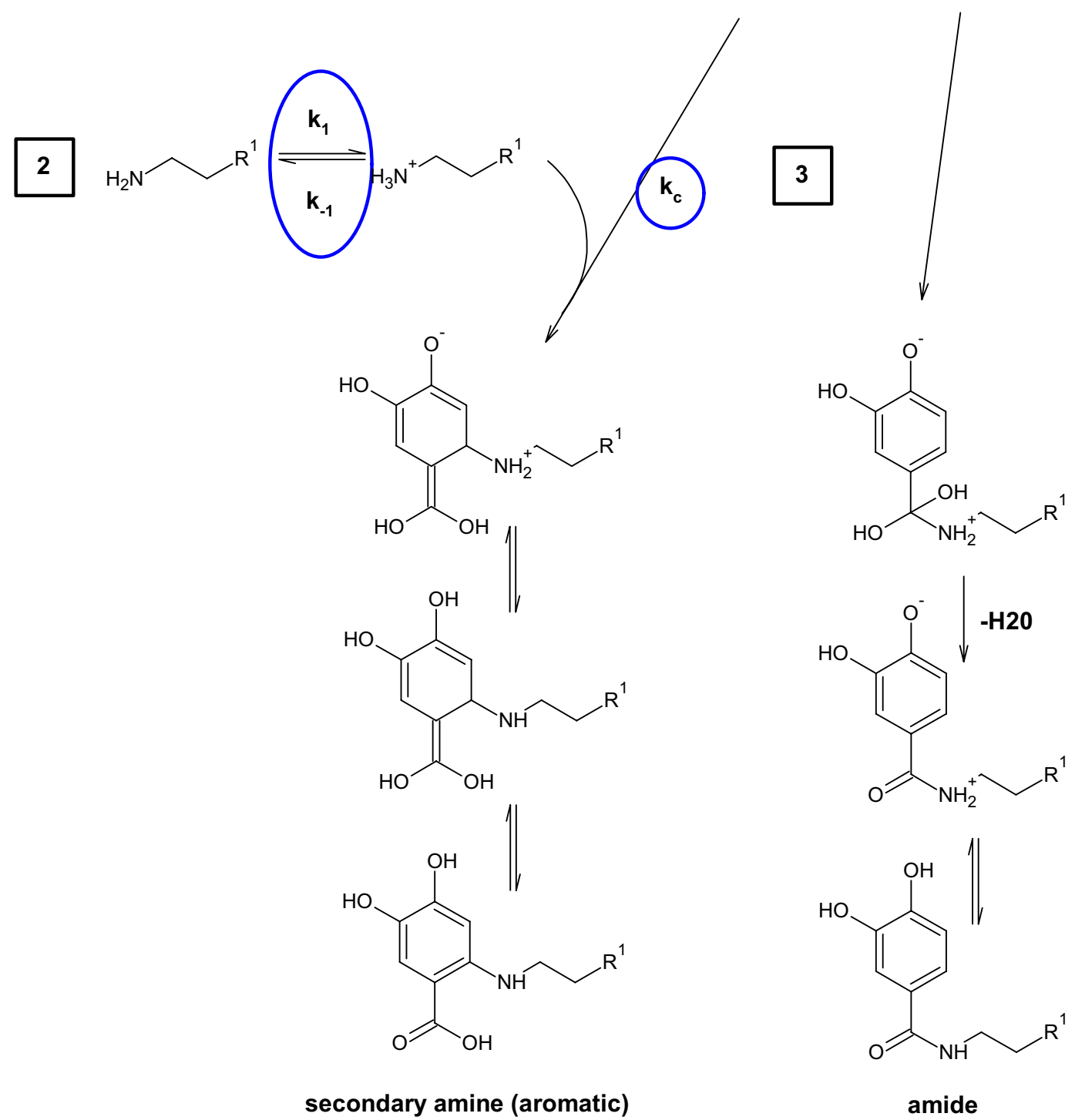

Fig. 4 Reaction model for the formation of intermolecular $\mathrm{C}-\mathrm{N}$ bonds between primary amines and PCA. Laccases initiate the formation of quinone methides by activating the catechol (step 1) [75]. The

approaches $\frac{1}{k_{c}}$. The equation can therefore be simplified to $\frac{1}{k} \approx \frac{1}{k_{c}}+\frac{1}{k_{1}}$. Hence, the reaction rate becomes independent specific rate constants $\mathrm{k}_{1}$ and $\mathrm{k}_{-1}$ are dependent on the $\mathrm{pKa}$ value of the primary amine (step 2). The specific rate constant $\mathrm{k}_{\mathrm{c}}$ is temperature dependant (3)

from the $\mathrm{pH}$ value. If the $\mathrm{pH}$ value is larger than the $\mathrm{pK}_{\mathrm{a}}$ of the primary amine, the term can be simplified to $\frac{1}{k} \approx \frac{1}{k_{1}}$. 
HPLC-MS analysis of the non-enzymatic incubation of DHC with NAcDAP at a $\mathrm{pH}$ above 5 has found a formation of a DHC-NAcDAP dimer. The observation that at pH 5.8, 6.2 and 8.2 increasing amounts of the dimer were detected are in agreement with this adjusted kinetic model. An increase of the $\mathrm{pH}$ led to a decreased concentration of $\mathrm{H}+$ ions and therefore increased the reaction rate $\mathrm{k}$.

Next to a high $\mathrm{pH}$, a low $\mathrm{pK}_{\mathrm{a}}$ value of the primary amine should be favourable for the conversion rate. If a primary amine is used with a $\mathrm{K}_{\mathrm{a}}$ value of $10^{-5}$ to $10^{-7} \mathrm{M}$ (at a neutral $\mathrm{pH})$, the $\mathrm{pH}$ of the reaction medium could be more or less neglected. Most primary amines have high $\mathrm{pK}_{\mathrm{a}}$ values of 9 or above, contrarily, chitosan has a $\mathrm{pK}_{\mathrm{a}}$ value of 6 to 7 . Consequently, spontaneous reaction with chitosan was expected at neutral or slightly acidic $\mathrm{pH}$ values.

\section{Spontaneous Reaction of Chitosan and DHC or PCA}

Chitosan contains a regular structure of glucosamine and $\mathrm{N}$-acetylglucoseamine monomers. The primary amines of the glucosamine units are good anchor points for functionalization with a catechol to form an adhesive mimicking the mussel's adhesion. The formation of the $\mathrm{C}-\mathrm{N}$ bond between a primary amine and the catechol is, as described in "Influence of the $\mathrm{pH}$ Value and the Primary Amines' pKa for $\mathrm{C}-\mathrm{N}$ Bond Formation to Catechols", favoured by a low $\mathrm{pK}_{\mathrm{a}}$ value of the primary amine. The $\mathrm{pK}_{\mathrm{a}}$ of chitosan is below 7 and therefore significantly lower than most primary amines (such as NAcDAP), which made it susceptible to spontaneous reaction. Following, the spontaneous reaction of chitosan with PCA and DHC was investigated.

\section{Solubility of Chitosan in the Presence of PCA and DHC}

For a homogeneous catalysis, complete solubility of chitosan and the catechol donor compounds was sought. The solubility of chitosan was dependent on the $\mathrm{pH}$ value and varied with its deacetylation degree and molecular weight. Interestingly, the presence of PCA and DHC had an effect on the solubility of chitosan as well. The $\mathrm{pH}-$ dependant solubility of chitosan in de-ionized water $\left(10 \mathrm{~g} \mathrm{~L}^{-1}\right)$ was determined by measuring the turbidity at $680 \mathrm{~nm}$. As shown in Fig. 5, chitosan became completely soluble at a $\mathrm{pH}$ around 5 . In the presence of either $25 \mathrm{~mol} \%$ (data not shown), $50 \mathrm{~mol} \%$ DHC or $25 \mathrm{~mol} \%$ PCA, complete solubility was already reached at a pH of 5.2. For a solution containing $50 \mathrm{~mol} \% \mathrm{PCA}$, complete solubility was only reached at $\mathrm{pH}$ 4.5. Overall, PCA as well as DHC had a notable influence on the solubility of chitosan, which indicated spontaneous reactions.

\section{Mid-infrared Analysis of Spontaneous $\mathrm{C}-\mathrm{N}$ bond Formation}

To further evaluate the spontaneous reaction of chitosan with PCA or DHC, FT-IR spectra were recorded directly after mixing, after $30 \mathrm{~min}$ ( $\mathrm{t} 1$, data not shown) and after $3 \mathrm{~h}(\mathrm{t} 2)$. First, a solution of $100 \mathrm{~g} \mathrm{~L}^{-1}$ chitosan was prepared at different $\mathrm{pH}$ values. The chitosan dissolved and formed a gel at a $\mathrm{pH}$ of 1,5 and 6 , but not at 9, resulting in a suspension of chitosan in de-ionized water. As shown in Fig. 6 A, only the gel form of chitosan was detectable using FT-IR measurements. Since PCA did not help to form a chitosan gel at $\mathrm{pH} 9$, the spontaneous reaction was not measurable. At $\mathrm{pH} 1$ and 5 some distinct peaks were formed (see Fig. 6b). At $\mathrm{pH} \mathrm{5}$, peaks at $1200 \mathrm{~cm}^{-1}, 1250 \mathrm{~cm}^{-1}$, $1288 \mathrm{~cm}^{-1}, 1363 \mathrm{~cm}^{-1}$ and $1546 \mathrm{~cm}^{-1}$ formed over time. At $\mathrm{pH} 1$, the peaks at $1250 \mathrm{~cm}^{-1}$ and $1288 \mathrm{~cm}^{-1}$ were shifted to lower and higher wave numbers respectively, while the
Fig. 5 pH-dependant solubility of chitosan $\left(10 \mathrm{~g} \mathrm{~L}^{-1}\right)$ in de-ionized water in the presence of DHC or PCA at different concentrations

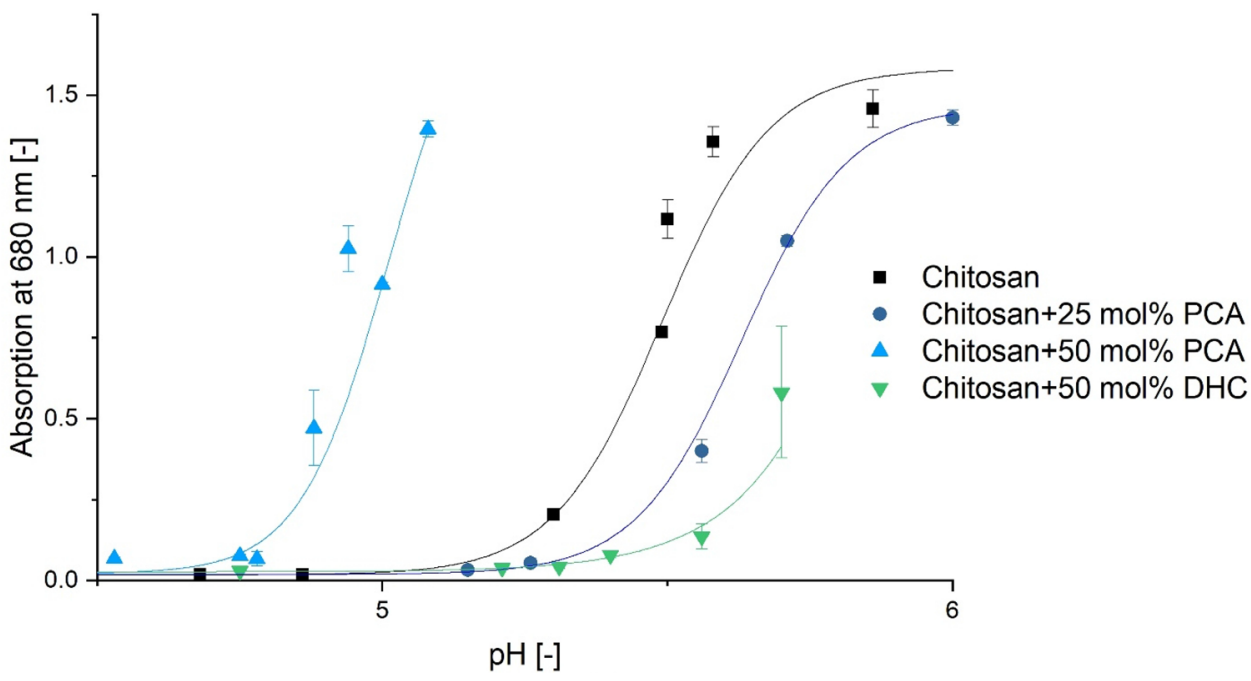



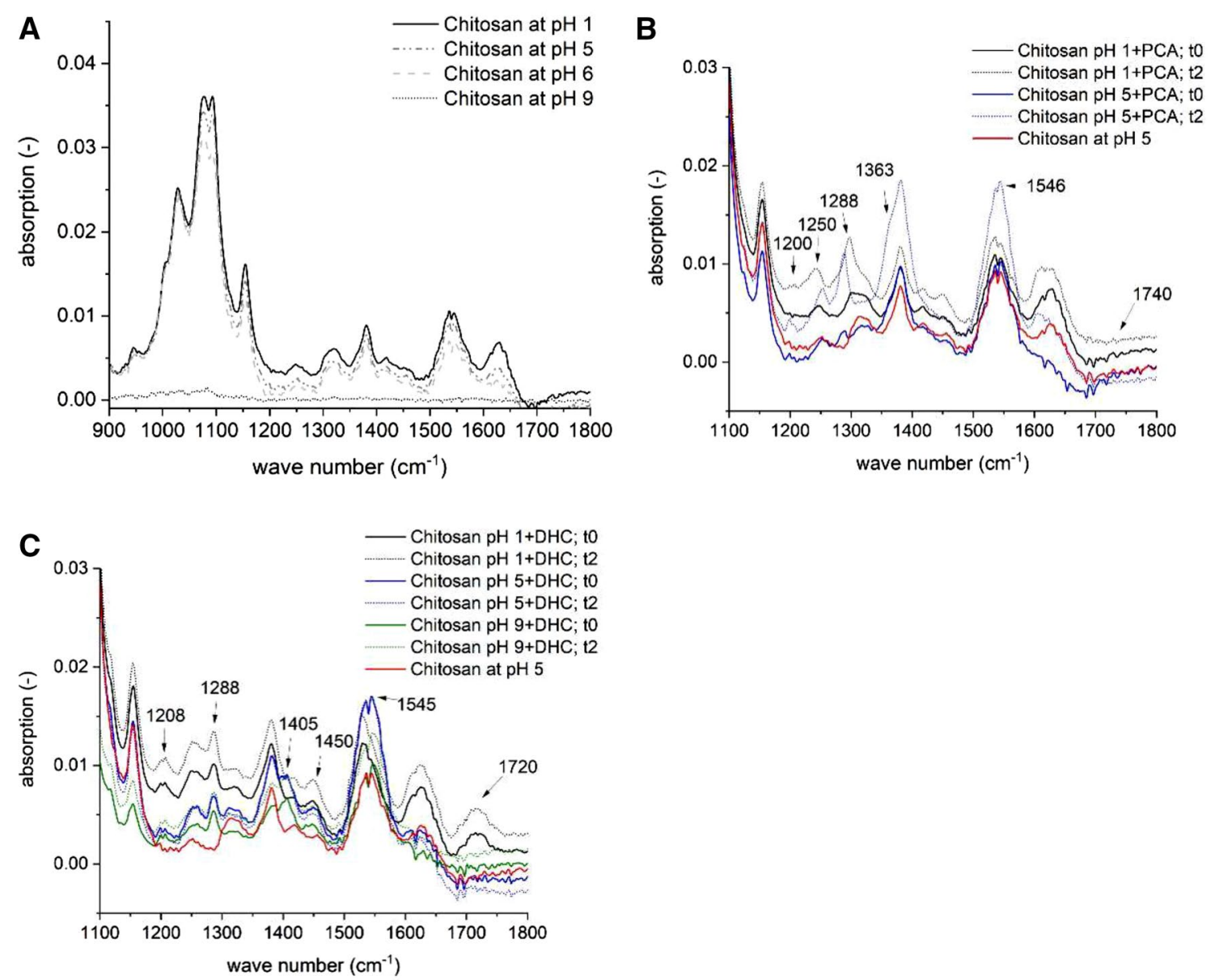

Fig. 6 FT-IR analysis of a chitosan at $\mathrm{pH} 1,5,6$ and 9; $\mathbf{b}$ chitosan at $\mathrm{pH}$ 1,5 and 9 after PCA addition and $\mathbf{c}$ chitosan at $\mathrm{pH} 1,5$ and 9 after DHC addition $(\mathrm{t} 0=$ reaction start, $\mathrm{t} 2=3 \mathrm{~h})$

peaks at $1363 \mathrm{~cm}^{-1}$ and $1546 \mathrm{~cm}^{-1}$ were no longer present. The peaks at $1250 \mathrm{~cm}^{-1}$ and $1288 \mathrm{~cm}^{-1}$ were attributed to the $\mathrm{C}-\mathrm{O}$ vibration bands of the catechol [58]. The absorption at $1363 \mathrm{~cm}^{-1}$ was attributed to the aromatic $\mathrm{C}-\mathrm{N}$ stretch band that is characteristic for secondary amines [76]. In contrary, characteristic for amides is a strong characteristic peak (amide II) at around 1510 to $1550 \mathrm{~cm}^{-1}$ that resulted from the $\mathrm{N}-\mathrm{H}$ deformation band [77]. The peak at $1546 \mathrm{~cm}^{-1}$ corresponded well with this area and could represent an amide bond. However, for catechol-functionalized chitosan $\mathrm{C}=\mathrm{O}$ stretch and $\mathrm{N}-\mathrm{H}$ bend of the amide bond was found at $1600 \mathrm{~cm}^{-1}$ and $1740 \mathrm{~cm}^{-1}$ as a result of ECD coupling [78]. Since those peaks were absent in this study, the peak at $1546 \mathrm{~cm}^{-1}$ might result from the amine's $\mathrm{N}-\mathrm{H}$ bend which is often found between 1580 and $1650 \mathrm{~cm}^{-1}$ [77]. As a result, it was concluded that Michael-type addition was predominant. Hence, the analysis of the FT-IR spectra concluded that aromatic $\mathrm{C}-\mathrm{N}$ bond were formed during the spontaneous reaction of chitosan and PCA at $\mathrm{pH}$ 5. For the reaction of chitosan with PCA, the absorption increased over the course of $3 \mathrm{~h}$, showing the reaction progress.
DHC mediated the formation of a chitosan gel at $\mathrm{pH} 9$, hence FT-IR analysis was possible for all $\mathrm{pH}$ values. At $\mathrm{pH}$ 1,5 and 9 , peaks were detected at $1208 \mathrm{~cm}^{-1},\left(1250 \mathrm{~cm}^{-1}\right)$, $1288 \mathrm{~cm}^{-1}, 1405 \mathrm{~cm}^{-1}$ and $1450 \mathrm{~cm}^{-1}$. The peaks at $1250 \mathrm{~cm}^{-1}$ and $1288 \mathrm{~cm}^{-1}$ were again attributed to the $\mathrm{C}-\mathrm{O}$ vibration bands of the catechol [58]. Since the peak at $1405 \mathrm{~cm}^{-1}$ was only present at $\mathrm{pH} 9$, it was likely attributed to an oxidation product of DHC [76]. For pH 5 and 9, a strong peak at $1545 \mathrm{~cm}^{-1}$ was present (see Fig. 6c), which again, corresponds well with either an amide or amine's $\mathrm{N}-\mathrm{H}$ bond, however, no peak that correlated well with the aromatic $\mathrm{C}-\mathrm{N}$ stretch band was observed. Only an absorption peak was found around $1450 \mathrm{~cm}^{-1}$ which might result from either $\mathrm{C}-\mathrm{H}$ bending (scissoring) of a methyl group or an aromatic $\mathrm{C}=\mathrm{C}$ stretching vibration band. However, analogously to the two peaks of the PCA-catechol $\left(1363 \mathrm{~cm}^{-1}\right.$ and $1546 \mathrm{~cm}^{-1}$ ), the peaks at $1450 \mathrm{~cm}^{-1}$ and $1545 \mathrm{~cm}^{-1}$ may result from the formation of an aromatic $\mathrm{C}-\mathrm{N}$ stretch band. Furthermore, for the reaction $\mathrm{pH}$ of 1 , peaks were found at $1640 \mathrm{~cm}^{-1}$ and $1720 \mathrm{~cm}^{-1}$, which correlated well with the amide bond described for catechol-functionalized chitosan 
[78]. Since chitosan formed a gel which draws water from the reaction mixture, amide formation might be possible in combination with DHC. Hence, the analysis of the FT-IR spectra concluded that both aromatic $\mathrm{C}-\mathrm{N}$ bonds, as well as amides were formed during the spontaneous reaction with DHC. In conclusion, the FT-infrared analysis of spontaneous $\mathrm{C}-\mathrm{N}$ bond formation confirmed the kinetic model introduced in 'Influence of the $\mathrm{pH}$ Value and the Primary Amines' $\mathrm{pKa}$ for C-N Bond Formation to Catechols". While at low $\mathrm{pH}$ levels ( $\mathrm{pH}$ 1), no $\mathrm{C}-\mathrm{N}$ bond formation was detected with PCA, for both catechols $\mathrm{C}-\mathrm{N}$ bonds were observed at $\mathrm{pH} 5$.

\section{Determination of pH-Dependant PCA Binding Capacity}

HPLC-MS analysis have shown that DHC was not stable and auto-catalytically formed quinones (see "Laccase Catalyzed Reaction with Model Compounds"), which have similar absorption maxima, but larger extinction coefficients than the corresponding catechols. Due to this instability, DHC was not suited for optical analysis. Therefore, the determination of the $\mathrm{pH}$-dependant catechol binding capacity was only conducted using PCA. In order to determine the $\mathrm{pH}$-dependant absorption of PCA onto chitosan, a solution of chitosan in de-ionized water $\left(10 \mathrm{~g} \mathrm{~L}^{-1}\right)$ was mixed with $25 \mathrm{~mol} \%$, $50 \mathrm{~mol} \%$ or $100 \mathrm{~mol} \%$ of PCA at pH 5 and $\mathrm{pH} \mathrm{6.5.} \mathrm{After}$ removal of the solid chitosan, the supernatant was analysed for its PCA concentration. As shown in Fig. 7, the absorption of PCA at a pH of 5 was preferred over the absorption at $\mathrm{pH}$ 6.5. For both $\mathrm{pH}$ values, more PCA per gram chitosan was absorbed at higher availability of PCA in the supernatant. The highest PCA absorption was reached after 15 min with $100 \mathrm{~mol} \%$ PCA. $0.45 \mathrm{~g}$ of PCA were absorbed per gram chitosan, which equals $60 \mathrm{~mol} \%$ of PCA per primary amine of chitosan.

The absorption of PCA was a fast reaction that occurred within $15 \mathrm{~min}$ after the PCA dissolved. After $3 \mathrm{~h}$ and $18 \mathrm{~h}$

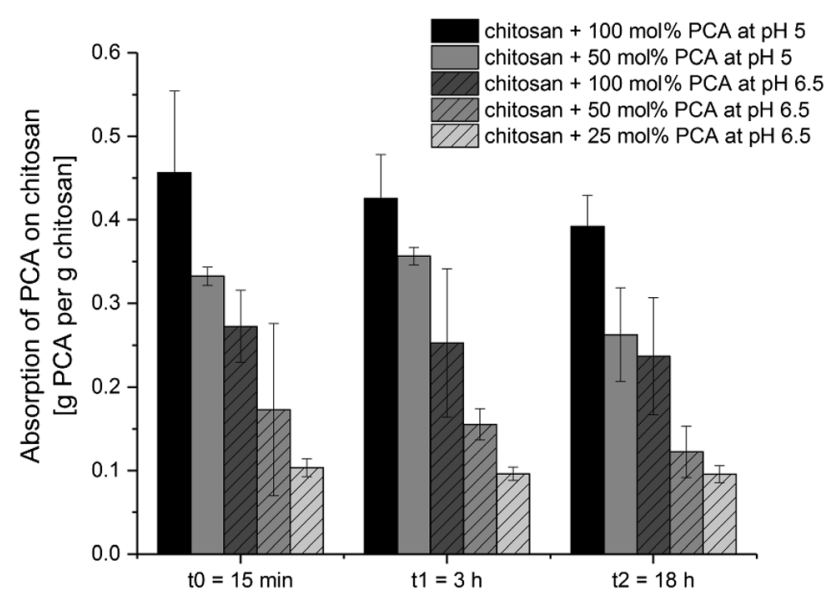

Fig. 7 pH-dependant PCA absorption onto chitosan of incubation, no significant change was detected. Generally, the absorption signal after $18 \mathrm{~h}$ decreased slightly, which may have been caused by a minor instability of PCA. As discussed in "Turbidity Measurements", at a pH of 5 and a molar concentration of $25 \mathrm{~mol} \%$ PCA, chitosan was completely dissolved and could not be separated by centrifugation. Hence, the absorption experiments confirmed the results of the IR-measurements. A spontaneous reaction occurred between PCA and chitosan.

\section{Influence of PCA and DHC on the Viscosity of Chitosan Solutions}

The viscosity of the adhesive was an important factor for the proper processing of the adhesive. On the one hand, the lower the viscosity of the adhesive, the easier it was, to wet the material surface. On the other hand, the lower the viscosity, the thinner (more fluid) was the adhesive and the higher the likelihood, that the adhesive flowed away before the curing process was completed.

Based on the kinetic model for the formation of $\mathrm{C}-\mathrm{N}$ bonds, a spontaneous reaction of chitosan and catechols was expected, which could lead to more cross-linking of chitosan molecules and therefore an increase of the viscosity. Following, the influence of PCA and DHC on the viscosity of a chitosan solution was investigated.

To determine the kinematic viscosity of the dissolved chitosan, the $\mathrm{pH}$ was chosen according to complete solubility as described in "Solubility of Chitosan in the Presence of PCA and DHC". As shown in Table 2, while the kinematic viscosity increased as soon as chitosan was soluble, the differences caused by the presence of PCA or DHC were minor.

\section{Gel Formation During Spontaneous and Enzyme Catalyzed Functionalization of Chitosan with DHC}

Even though no effect on the viscosity was found after shortterm incubation of chitosan with PCA and DHC, it was

Table 2 Kinematic viscosity (at $30{ }^{\circ} \mathrm{C}$ ) of chitosan solutions in the presence of DHC or PCA

\begin{tabular}{lll}
\hline Component & $\mathrm{pH}[-]$ & $\begin{array}{l}\text { Kinematic } \\
\text { viscosity }\left[\mathrm{mm}^{2}\right. \\
\left.\mathrm{s}^{-1}\right]\end{array}$ \\
\hline Chitosan & 4.8 & $69.9 \pm 2.4$ \\
Chitosan & 4.8 & $55.3 \pm 0.6$ \\
Chitosan (not dissolved) & 5.0 & $14.9 \pm 0.4$ \\
Chitosan +25 mol\% PCA & 5.2 & $50.0 \pm 1.1$ \\
Chitosan +50 mol\% PCA & 4.5 & $59.6 \pm 1.5$ \\
Chitosan + 25 mol\% DHC & 5.2 & $57.3 \pm 0.3$ \\
Chitosan +50 mol\% DHC & 5.2 & $58.8 \pm 0.3$ \\
\hline
\end{tabular}


noted that after 24 to $48 \mathrm{~h}$ of reaction time, DHC was able to cross-link chitosan, resulting in a viscous gel. Following, the spontaneous reaction (no enzyme) of chitosan and DHC, as well as a mild treatment with laccase $(0.1 \mathrm{vol} \%)$ and strong laccase treatment (1.0 vol\%) were compared.

As shown in Fig. 8, the solution without laccase turned slightly pink after about three hours of incubation, red with $0.1 \%$ laccase and dark red with $1 \%$ laccase. The solution with $1.0 \mathrm{vol} \%$ laccase had already formed a gel at $3 \mathrm{~h}$ of incubation. After further incubation $(3 \mathrm{~h})$, a gel had formed with $0.1 \mathrm{vol} \%$ laccase as well (data not shown). After a total incubation time of $24 \mathrm{~h}$, a gel was also visible for the spontaneous reaction. However, at this point, the hydrogel catalyzed by $1.0 \mathrm{vol} \%$ laccase had solidified and a black residue had formed, which can be attributed to oxidized catechols (quinones). After a further $48 \mathrm{~h}$, the gel of the $0.1 \mathrm{vol} \%$ laccase solution had also oxidized. The gel formation is an indicator for cross-links of chitosan molecules via DHC. Hence, the DHC can contribute to cohesion, but lacks the ability to adhere to surfaces. Is was shown, that the treatment with laccase accelerated the cross-linking of chitosan, but also led to quinone formation, which was undesirable for both cohesion and adhesion.

\section{Formation of Chitosan-Agglomerates During Enzyme Catalyzed Functionalization with PCA}

North et al. (2017) have shown that for poly-catechol-styrene strong adhesion $(>2 \mathrm{MPa})$ required a catechol content of at least $20 \mathrm{~mol} \%$ [9]. While the cross-linking of chitosan via catechols resulted in a higher polymerisation degree, which is usually beneficial for cohesion, in this case the loss of the functionality of the primary catechol group was an issue. The formation of a gel or agglomerates was an indicator for such cross-linking processes.

For chitosan and PCA (with and without enzyme treatment) no gel formation was observed (data not shown). In order to investigate the effect of PCA on the formation of chitosan agglomerates, particle size development over time was investigated. Particle size characterization was conducted via particle sizer (LumiReader) and validated using microscopy imaging. The results are shown in Table 3. The comparison of the data obtained for the control experiments (90 min, no enzyme) showed a median of $3.8 \mu \mathrm{m}$ from microscopy imaging and $3.5 \mu \mathrm{m}$ from the particle sizer. According to the microscopy results, $10 \%$ of particles were smaller than $1.5 \mu \mathrm{m}$ (D0.1), 90\% of particles were smaller than $11.5 \mu \mathrm{m}$ (D0.9) and had a span of $2.6 \mu \mathrm{m}$. (The span is defined as (D0.1-D0.9)/D0.5 and quantified the distribution width.) Using the particle sizer, $10 \%$ of particles were smaller than $2.4 \mu \mathrm{m}$ and $90 \%$ of particles were smaller than
$\mathrm{T} 2=3 \mathrm{~h}$

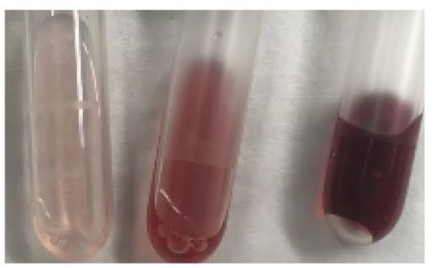

$\mathrm{T} 4=24 \mathrm{~h}$

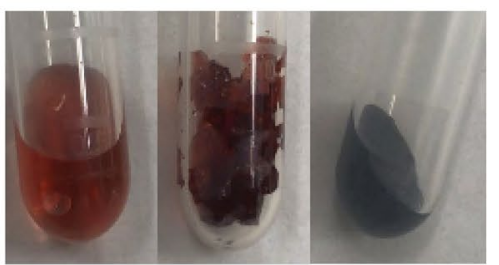

$\mathrm{T} 5=48 \mathrm{~h}$

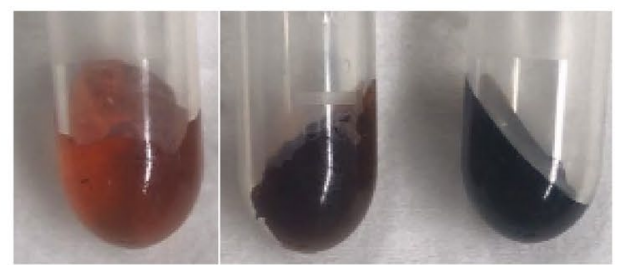

Fig. 8 Gel formation of a chitosan solution containing DHC at pH 5 after $3 \mathrm{~h}, 24 \mathrm{~h}$ and $48 \mathrm{~h}$. At each point in time, the spontaneous reaction, mild treatment with laccase $(0.1 \mathrm{vol} \%)$ and strong laccase treatment (1.0 vol\%) are shown from left to right

Table 3 Particle size characterisation of PCA-chitosan agglomerates after enzyme treatment

\begin{tabular}{|c|c|c|c|c|c|c|c|}
\hline & Sample & Data points & Median $(\mu \mathrm{m})$ & D0.1 ( $\mu \mathrm{m})$ & $\mathrm{D} 0.5(\mu \mathrm{m})$ & $\mathrm{D} 0.9(\mu \mathrm{m})$ & Span $(\mu \mathrm{m})$ \\
\hline \multirow[t]{3}{*}{ Microscopy imaging } & Control (90 min) & 132 & $3.8 \pm 5.6$ & 1.5 & 3.8 & 11.5 & 2.6 \\
\hline & Enzyme treated $(90 \mathrm{~min})$ & 100 & $6.9 \pm 54.5$ & 1.4 & 6.9 & 75.4 & 10.8 \\
\hline & Enzyme treated $(24 \mathrm{~h})$ & 105 & $19.9 \pm 64.8$ & 4.0 & 19.9 & 107.2 & 5.2 \\
\hline \multirow[t]{5}{*}{ Particle sizer } & Control (90 min) & 3 & $3.4 \pm 5.8$ & 2.2 & 3.4 & 12 & 2.9 \\
\hline & Control (90 min) & 3 & $3.5 \pm 6.9$ & 2.4 & 3.5 & 11.2 & 2.5 \\
\hline & Control (90 min) & 2 & $3.7 \pm 6.6$ & 2.3 & 3.7 & 11.2 & 2.4 \\
\hline & Enzyme treated $(90 \mathrm{~min})$ & 2 & $14.9 \pm 18.9$ & 5.9 & 14.9 & 53.8 & 3.2 \\
\hline & Enzyme treated $(24 \mathrm{~h})$ & 3 & $14.1 \pm 15.5$ & 5.4 & 14.1 & 40.6 & 2.5 \\
\hline
\end{tabular}

The incubation was completed at $28^{\circ} \mathrm{C}$, at $\mathrm{pH} 5$ 
$11.2 \mu \mathrm{m}$, resulting in a span of $2.5 \mu \mathrm{m}$. It was clearly shown, that the particle size increased significantly due to enzyme incubation.

The particles size of PCA-chitosan agglomerates without addition of the enzyme was analysed as well. No significant increase of particle size was detected within $90 \mathrm{~min}$. The formation of agglomerates was therefore due to the enzyme treatment. Due to laccase treatment, the PCA likely functioned as a linker between two or more chitosan molecules, furthering cohesion, but making it less available for surface adhesion. For surface adhesion on aluminium, where the catechol group was a key element, laccase-treatment was therefore contra productive, resulting in a complete loss of adhesion strength.

\section{Adhesion Performance of PCA-Chitosan Adhesive}

This study has demonstrated spontaneous reactions occurring between chitosan and the catechols PCA or DHC. A theoretical model identified the most significant reaction parameters, $\mathrm{pKa}$ of the amine as well as the reaction $\mathrm{pH}$. Due to the relatively low $\mathrm{pKa}$ of chitosan, no catalyst was needed and spontaneous reaction was possible at neutral or slightly acidic $\mathrm{pH}$ values. DHC was able to cross-link chitosan via spontaneous $\mathrm{C}-\mathrm{N}$ bond formation, which led to an increased cohesion, but complete loss of adhesion (data not shown). Therefore, adhesion experiments in this section were conducted using the PCA-chitosan adhesive.

During the curing of the adhesive, three processes are assumed to occur simultaneously: The water evaporates, promoting covalent bond formation between the chitosan and the catechol monomers. The catechol groups bond to the aluminium cylinders in order to establish surface adhesion and oxidized catechols (quinone) react with each other, forming covalent adhesion bonds.

\section{The $\mathrm{pH}$ Value During Binding}

Chitosan solubilized in acidic solutions and formed a gel, which was necessary for homogeneous catalysis. The gel formation of chitosan occurred at $\mathrm{pH}$ values below 5.5. However, according to the kinetic model (see "Influence of the $\mathrm{pH}$ Value and the Primary Amines' pKa for $\mathrm{C}-\mathrm{N}$ Bond Formation to Catechols"), the spontaneous $\mathrm{C}-\mathrm{N}$ bond formation was preferred at higher $\mathrm{pH}$ values and did not occur at a $\mathrm{pH}$ of 1 (see "Mid-infrared Analysis of Spontaneous $\mathrm{C}-\mathrm{N}$ bond Formation"). Therefore, the optimal $\mathrm{pH}$ for adhesion of the PCA-chitosan agglomerate was expected to be between 4 and 5 . In order to further validate the kinetic model and to find the optimal $\mathrm{pH}$ value during binding, different $\mathrm{pH}$ values were tested during binding. The $\mathrm{pH}$ values tested were 1.21; 4.70; 5.03 and 5.41. As shown in Fig. 9, the adhesion achieved with chitosan itself (without PCA) was $0.23 \pm 0.13 \mathrm{MPa}$.

For PCA-chitosan at a pH of 1.21, an adhesion strength of $0.20 \pm 0.13 \mathrm{MPa}$ was measured, an insignificant increase of the adhesion strength as compared to the chitosan control. This was in agreement with the results of the FT-IR-spectroscopy (see "Mid-infrared Analysis of Spontaneous C-N bond Formation"), which suggested that the $\mathrm{C}-\mathrm{N}$ bond formation did not occur at a $\mathrm{pH}$ of 1 . The adhesion strengths of the PCA-chitosan adhesive at $\mathrm{pH} 4.70$ and 5.03 were similar at $3.40 \pm 0.32 \mathrm{MPa}$ and $3.41 \pm 0.12 \mathrm{MPa}$, respectively. At $\mathrm{pH}$ 5.41 , the adhesion strength measured was significantly lower $(2.27 \pm 0.40 \mathrm{MPa})$. Since chitosan was only partially soluble at $\mathrm{pH}>5$, the lower solubility likely had an impact on the adhesion strength. As HPLC-MS measurements showed, that PCA was stable for at least $24 \mathrm{~h}$ at a $\mathrm{pH}$ of 6.5 , the lower adhesion strength was not attributed to initial degradation of the functional PCA group. The kinetic model for the prediction of $\mathrm{C}-\mathrm{N}$ bonds seemed to be valid for the spontaneous formation of a PCA-chitosan adhesive.

\section{Adhesion Gap and Surface Preparation}

The novel PCA-chitosan adhesive had a solid content of only $12 \mathrm{wt} \%$. Therefore, significant loss of mass occurred during the curing process. This led to a decreased adhesion strength when using a defined adhesion gap of $0.5 \mathrm{~mm}$. As shown in Fig. 10, the adhesion declines from $1.79 \pm 0.36$ to $0.83 \pm 0.39 \mathrm{MPa}$ due to the use of a defined adhesion gap.

The comparison of the adhesion strength due to surface preparation was shown in Fig. 10. A ground surface resulted

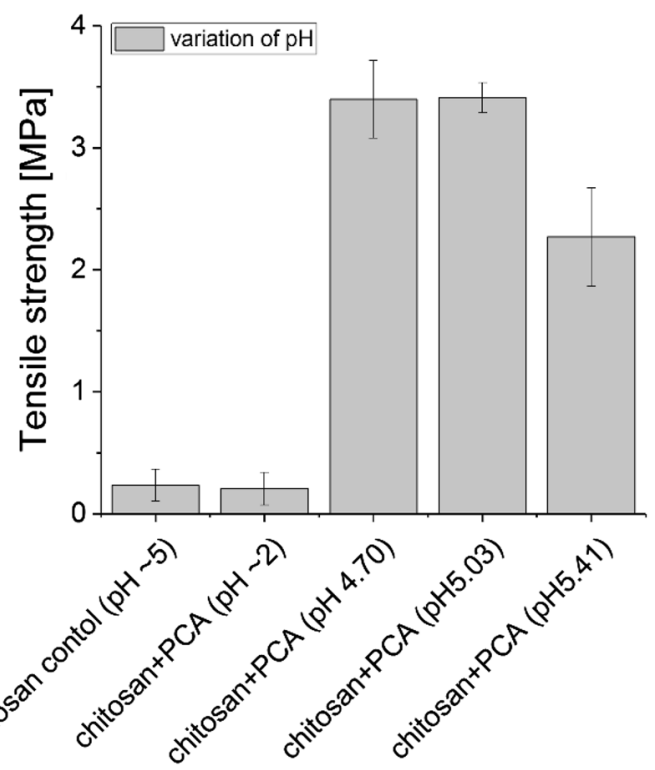

Fig. 9 Tensile strength of chitosan and PCA-chitosan adhesives with different $\mathrm{pH}$ values 


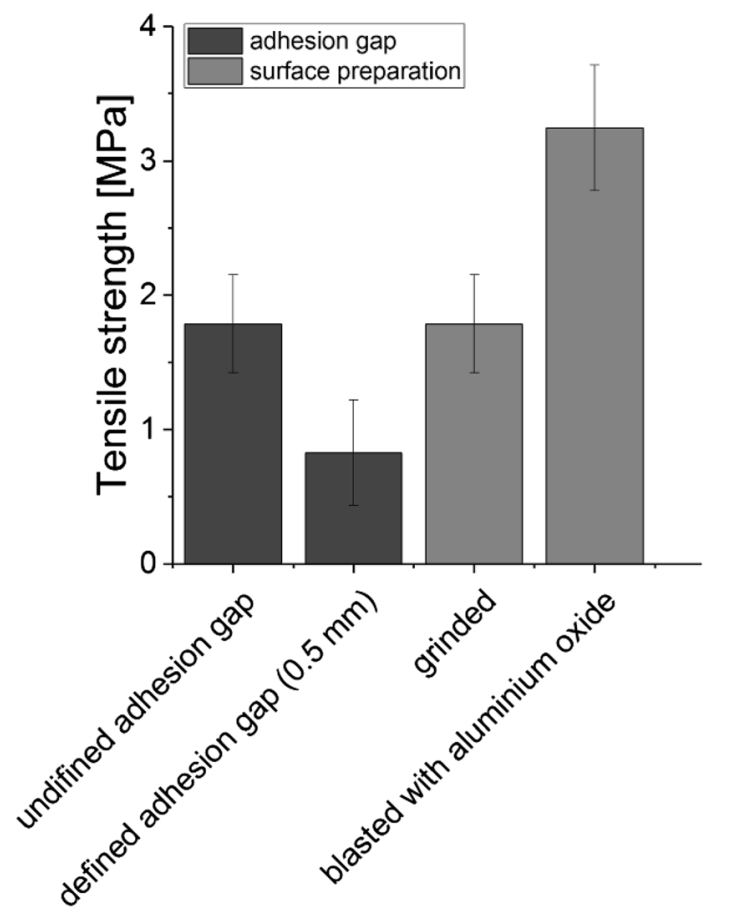

Fig. 10 Adhesion gap and surface preparation effects on tensile strength of the PCA-chitosan adhesive. An adhesion gap is the length between the adhesion surfaces

in a surface adhesion of only $1.79 \pm 0.36 \mathrm{MPa}$, while a sand blasted surface, using aluminum oxide, increased the adhesion to $3.25 \pm 0.47 \mathrm{MPa}$. The average roughness of the ground surface was determined to be $\mathrm{Ra}=0.73 \pm 0.09 \mu \mathrm{m}$ and $\mathrm{Ra}=0.61 \pm 0.11 \mu \mathrm{m}$ for the blasted surface. Since no significant increase of surface roughness was observed due to blasting, the increased adhesion strength was likely caused by differences in the aluminium oxide surface layer. In the next sections, adhesion testing was performed on surfaces that were blasted with aluminum oxide.

\section{Filler Materials}

Due to the high viscosity of the chitosan, the final concentration of polymer in the catechol-chitosan adhesive was only about $12 \mathrm{wt} \%$. In order to increase the solid concentration, filler materials were used. Here, the tensile strength of the catechol-chitosan was tested, after adding $1 \mathrm{wt} \%$ and $2 \mathrm{wt} \%$ of cotton, as well as $1 \mathrm{wt} \%, 2 \mathrm{wt} \%$ and $4 \mathrm{wt} \%$ of OS-lignin. While most filler materials decreased the tensile strength, $2 \mathrm{wt} \%$ OS-lignin had no negative impact on the tensile strength (see Fig. 11).

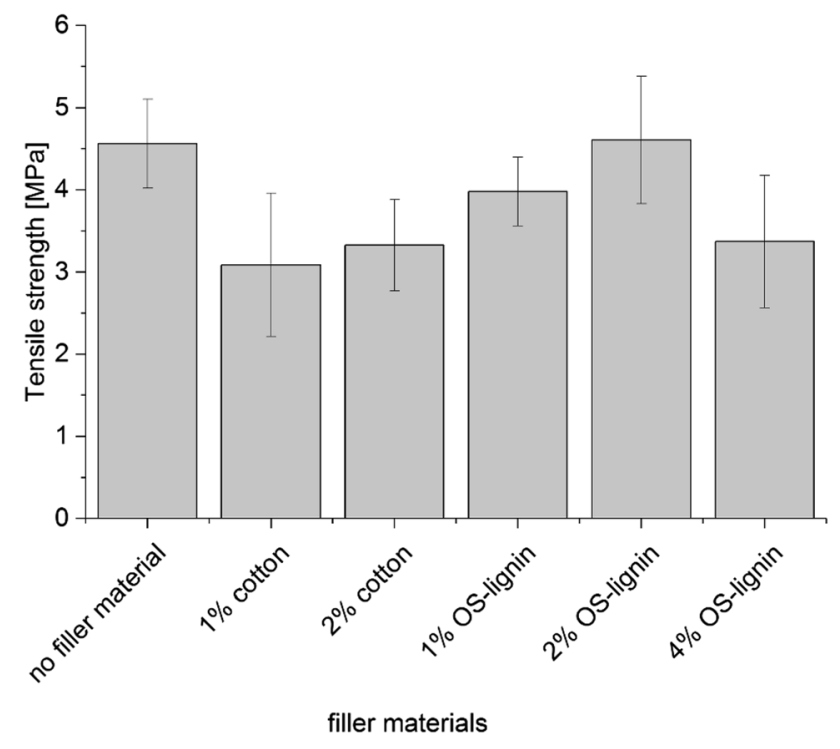

Fig. 11 Tensile strength of PCA-chitosan adhesive after adding cotton or OS-lignin as filler materials

\section{Comparison to Other Bio-adhesives}

Adhesives made from renewable resources have been used for hundreds of years [79]. In order to assess the adhesion strength obtained, a comparison with commercially available adhesives from renewable resources was presented. The adhesion strengths of dextrin, starch and Gummi arabicum compared to chitosan and the PCA-chitosan adhesive, are presented in Fig. 12. Dextrin and starch showed relatively low adhesion strengths $(0.35 \pm 0.17 \mathrm{MPa}$ and $0.50 \pm 0.17 \mathrm{MPa}$ after 3 days of curing at $\left.40{ }^{\circ} \mathrm{C}\right)$. G. arabicum was significantly higher at $2.10 \pm 0.45 \mathrm{MPa}$. The PCA-chitosan adhesive attained an adhesion strength of $4.56 \pm 0.54 \mathrm{MPa}, 2.2$ times higher than the adhesion strength of $G$. arabicum.

\section{Future Work}

The water based nature of chitosan and PCA, however, resulted in a lack of long-term water resistance. In future work, water resistance should be addressed, for example through laccase treatment. Furthermore, if the concentrations of the components are optimized in order to minimize side product and quinone formation caused by the laccase treatment, laccases could be used to accelerate the reaction rate. 


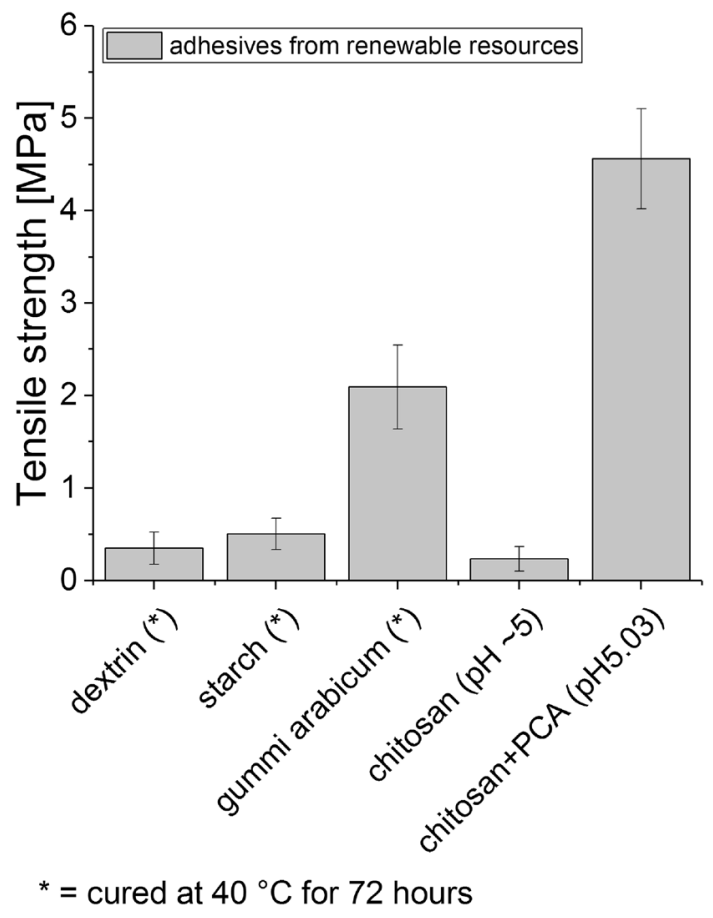

Fig. 12 Tensile strength of commercially available adhesives made from renewable resources and PCA-chitosan adhesive. Note: In a comparable setup for PCA alone, no significant adhesion was detected

\section{Conclusion}

In this work, the development of a mussel mimicking and biogenic adhesive was achieved by functionalizing chitosan with PCA via spontaneous Michael-type addition. Using model compounds, it was demonstrated that the dimerization of primary amines and catechols via Michael-type addition is catalyzed by laccases. From the investigation of a kinetic model for intermolecular $\mathrm{C}-\mathrm{N}$ bond formation between primary amines and catechols, it was concluded that the reaction is promoted by a low pKa value of the primary amine used and a neutral or mildly acidic reaction $\mathrm{pH}$. It was proposed that, due to the comparably low pKa of chitosan (below 7), spontaneous reaction occurred between chitosan and catechols.

Laccase-catalyzed $\mathrm{C}-\mathrm{N}$ bond formation between chitosan and catechols accelerated the reaction and promoted the formation of PCA-chitosan agglomerates and DHC-chitosan hydrogels. The result for DHC-chitosan was a highly crosslinked chitosan with limited adhesion properties. Moreover, the intense incubation with laccase resulted in the conversion of the catechol to its oxidized form, the quinone, resulting in complete loss of functionality. Therefore, spontaneous reaction over laccase-catalyzed Michael-type addition was superior for the development of our adhesive.
Compared to biogenic adhesives, the developed PCA-chitosan adhesive attained a strong adhesion of $4.56 \pm 0.54 \mathrm{MPa}$, which is 2.2 times higher than the adhesion strength of $G$. arabicum, the second best biogenic adhesive tested.

Acknowledgements Open Access funding provided by Projekt DEAL. The research results were obtained in the joint project BioBond funded by the Federal Ministry of Food and Agriculture (BMEL) through the Agency of Renewable Resources FNR e. V. (funding codes 22030514 and 22004615).

Open Access This article is licensed under a Creative Commons Attribution 4.0 International License, which permits use, sharing, adaptation, distribution and reproduction in any medium or format, as long as you give appropriate credit to the original author(s) and the source, provide a link to the Creative Commons licence, and indicate if changes were made. The images or other third party material in this article are included in the article's Creative Commons licence, unless indicated otherwise in a credit line to the material. If material is not included in the article's Creative Commons licence and your intended use is not permitted by statutory regulation or exceeds the permitted use, you will need to obtain permission directly from the copyright holder. To view a copy of this licence, visit http://creativecommons.org/licenses/by/4.0/.

\section{References}

1. Floriolli, R.Y., Von Langen, J., Waite, J.H.: Marine surfaces and the expression of specific byssal adhesive protein variants in Mytilus. Mar. Biotechnol. 2(4), 352-363 (2000)

2. Zhao, H., Sun, C., Stewart, R.J., Waite, J.H.: Cement proteins of the tube-building polychaete Phragmatopoma californica. J. Biol. Chem. 280(52), 42938-42944 (2005)

3. Miserez, A., Schneberk, T., Sun, C., Zok, F.W., Herbert, J.: NIH Public Access 319(5871), 1816-1819 (2009)

4. Waite, J.H., Tanzer, M.L.: Polyphenolic substance of Mytilus edulis: novel adhesive containing L-DOPA and hydroxyproline. Science 212(4498), 1038-1040 (1981)

5. Waite, J.H.: Adhesion a la moule. Biochemistry 1180, 1172-1180 (2002)

6. Lee, B.P., Messersmith, P.B., Israelachvili, J.N., Waite, J.H.: Mussel-inspired adhesives and coatings. Annu. Rev. Mater. Res. 41(1), 99-132 (2011)

7. Waite, J.H., Qin, X.: Polyphosphoprotein from the adhesive pads of Mytilus edulis. Biochemistry 40(9), 2887-2893 (2001)

8. Jia, M., Li, A., Mu, Y., Jiang, W., Wan, X.: Synthesis and adhesive property study of polyoxetanes grafted with catechols via $\mathrm{Cu}(\mathrm{I})$ catalyzed click chemistry. Polymer 55(5), 1160-1166 (2014)

9. North, M.A., Del Grosso, C.A., Wilker, J.J.: High strength underwater bonding with polymer mimics of mussel adhesive proteins. ACS Appl. Mater. Interfaces. 9(8), 7866-7872 (2017)

10. Kayano, S.I., Kikuzaki, H., Fukutsuka, N., Mitani, T., Nakatani, N.: Antioxidant activity of prune (Prunus domestica L.) constituents and a new synergist. J. Agric. Food Chem. 50(13), 3708$3712(2002)$

11. Maiti, B., Thomas, P., Nair, P.M.: High-performance liquid chromatography determination of phenolic acids in potato tubers (Solanum tuberosum) during wound healing. J. Agric. Food Chem. 40, 569-572 (1992)

12. Masella, R., Cantafora, A., Modesti, D., Cardilli, A., Gennaro, L., Bocca, A., Coni, E.: Antioxidant activity of 3,4-DHPEA-EA and 
protocatecuic acid: a comparative assessment with other olive oil biophenols. Redox Rep. 4(3), 113-121 (1999)

13. Masella, R., Varı, R., Archivio, M., et al.: Nutrient-gene interactions extra virgin olive oil biophenols inhibit cell-mediated oxidation of LDL by increasing the mRNA transcription of glutathionerelated enzymes. J. Nutr. 1, 785-791 (2004)

14. Kakkar, S., Bais, S.: A review on protocatechuic acid and its pharmacological potential. ISRN Pharmacol. 2014, 1-9 (2014)

15. Vitaglione, P., Donnarumma, G., Napolitano, A., Galvano, F., Gallo, A., Scalfi, L., Fogliano, V.: Protocatechuic acid is the major human metabolite of cyanidin-glucosides. J. Nutr. 137(9), 2043-2048 (2007)

16. Holden, M.: Processing of raw cocoa III. Enzymic aspects of cocoa fermentation. J. Sci. Food Agric. 10(12), 691-700 (1959)

17. Chandra, S., De Mejia, E.G.: Polyphenolic compounds, antioxidant capacity, and quinone reductase activity of an aqueous extract of Ardisia compressa in comparison to mate (llex paraguariensis) and green (Camellia sinensis) teas. J. Agric. Food Chem. 52(11), 3583-3589 (2004)

18. Chao, C.-Y., Yin, M.-C.: Antibacterial effects of roselle calyx extracts and protocatechuic acid in ground beef and apple juice. Foodborne Pathog. Dis. 6(2), 201-206 (2009)

19. Xican, Li, Wang, X., Chen, D., Chen, S.: Antioxidant activity and mechanism of protocatechuic acid in vitro. Funct. Foods Health Dis. 1(7), 232-244 (2011)

20. Tanaka, T., Tanaka, T., Tanaka, M.: Potential cancer chemopreventive activity of protocatechuic acid. J. Exp. Clin. Med. 3(1), 27-33 (2011)

21. Lende, A.B., Kshirsagar, A.D., Deshpande, A.D., Muley, M.M., Patil, R., et al.: Anti-inflammatory and analgesic activity of protocatechuic acid in rats and mice. Inflammopharmacology 19(5), 255-263 (2011)

22. Pacheco-Palencia, L.A., Mertens-Talcott, S., Talcott, S.T.: Chemical composition, antioxidant properties, and thermal stability of a phytochemical enriched oil from Acai (Euterpe oleracea Mart.). J. Agric. Food Chem. 56, 4631-4636 (2008)

23. Dannenfelser, R.M., Yalkowsky, S.H.: Data base of aqueous solubility for organic non-electrolytes. Sci. Total Environ. 109-110, 625-628 (1991)

24. Serjeant, E.P., Dempsey, B.: Ionisation constants of organic acids in aqueous solution, IUPAC chemical data series. Pergamon Press, Michigan (1979)

25. Dawson, R.M.C., Dawson, R.M.C.: Data for Biochemical Research Data for Biochemical Research. Clarendon Press, Oxford (1989)

26. Fugmann, B., Adam, G., Anke, H., Boland, W., Francke, W.: Römpp Lexikon Naturstoffe. Thiemen, Stuttgart (2014)

27. Kang, S.-Y., Choi, O., Lee, J., Hwang, B., Uhm, T.-B., Hong, Y.-S.: Artificial biosynthesis of phenylpropanoic acids in a tyrosine overproducing Escherichia coli strain. Microb. Cell Factories 11(1), 153 (2012)

28. Srinivasan, P.R., Shigeura H.T., Sprecher M., Sprinson D.B., Davis B.D.: The biosynthesis of shikimic acid from D-glucose. J. Biol. Chem. 220(1), 477-497 (1956)

29. Herrmann, K.M., Weaver, L.M.: The Shikimate Pathway. Annu. Rev. Plant Physiol. Plant Mol. Biol. 50(1), 473-503 (1999)

30. Ikeda, M., Katsumata, R., Tijsseling, L., Hoefnagel, M.H.N., Hugenholtz, J.: Metabolic engineering to produce tyrosine or phenylalanine in a tryptophan-producing Corynebacterium glutamicum strain. Appl. Environ. Microbiol. 58(3), 781-785 (1992)

31. Louie, G.V., Bowman, M.E., Moffitt, M.C.C., Baiga, T.J., Moore, B.S.S., Noel, J.P.: Structural determinants and modulation of substrate specificity in phenylalanine-tyrosine ammonia-lyases. Chem. Biol. 13(12), 1327-1338 (2006)
32. Peppercorn, M.A., Goldman, P.: Caffeic acid metabolism by bacteria of the human gastrointestinal tract. J. Bacteriol. 108(3), 996-1000 (1971)

33. Moon, J.-H., Terao, J.: Antioxidant activity of caffeic acid and dihydrocaffeic acid in lard and human low-density lipoprotein. J. Agric. Food Chem. 46, 5062-5065 (1998)

34. Roberts, G.A.F.: Chitin Chemistry. Macmillan Education, London (1992)

35. Elieh-Ali-Komi, D., Hamblin, M.R.: Chitin and chitosan: production and application of versatile biomedical nanomaterials. Int. J. Adv. Res. 4(3), 411-427 (2016)

36. Joshi, M., Purwar, R., Ali, W., Rajendran, S.: Antimicrobial textiles for health and hygiene applications based on eco-friendly natural products. Med. Healthcare Text. 2010, 84-92 (2010)

37. Kafetzopoulos, D., Martinou, A., Bouriotis, V.: Bioconversion of chitin to chitosan: purification and characterization of chitin deacetylase from Mucor rouxii. Proc. Natl. Acad. Sci. USA 90(7), 2564-2568 (1993)

38. Aiba, Si: Preparation of $N$-acetylchitooligosaccharides by hydrolysis of chitosan with chitinase followed by $\mathrm{N}$-acetylation. Carbohydr. Res. 265(2), 323-328 (1994)

39. Park, B., et al.: Applications of chitin and its derivatives in biological medicine. Int. J. Mol. Sci. 11(12), 5152-5164 (2010)

40. Shahidi, F., et al.: Food applications of chitin and chitosans. Trends Food Sci. Technol. 10(2), 37-51 (1999)

41. Krajewska, B.: Application of chitin- and chitosan-based materials for enzyme immobilizations: a review. Enzyme Microb. Technol. 35(2-3), 126-139 (2004)

42. Songkroah, C., Nakbanpote, W., Thiravetyan, P.: Recovery of silver-thiosulphate complexes with chitin. Process Biochem. 39(11), 1553-1559 (2004)

43. Hirano, S., Nakahira, T., Nakagawa, M., Kim, S.K.: The preparation and applications of functional fibres from crab shell chitin. Prog. Ind. Microbiol. 35, 373-377 (1999)

44. Hirano, S.: Wet-spinning and applications of functional fibers based on chitin and chitosan. Macromol. Symp. 168(1), 21-30 (2001)

45. Rinaudo, M., Pavlov, G., Desbrie, J., Desbrières, J.: Influence of acetic acid concentration on the solubilization of chitosan. Polymer 40, 7029-7032 (1999)

46. Sogias, I.A., Khutoryanskiy, V.V., Williams, A.C.: Exploring the factors affecting the solubility of chitosan in water. Macromol. Chem. Phys. 211(4), 426-433 (2010)

47. Katchalsky, A., Spitnik, P.: Potentiometric titrations of polymethacrylic acid. J. Polym. Sci. 2(4), 432-446 (1947)

48. Muzzarelli, R.A.A.: Chitin Chemistry. Elsevier, Amsterdam (1977)

49. Noguchi, J., Arato, K., Komai, T.: Chitosan-Epichlorohydrin Anion Exchange Resin with Primary Amine as Absroption Site. The Journal of the Society of Chemical Industry, Japan 72(3), 796-799 (1969)

50. Muzzarelli, R.A.A., Tanfani, F., Scarpini, G.I.: Chelating, film-forming, and coagulating ability of the chitosan-glucan complex from Aspergillus niger industrial wastes. Biotechnol. Bioeng. 22(4), 885-896 (1980)

51. Tamura, Z., Miyazaki, M., Suzuki, T.: Metal complexes of d-glucosamine and its derivatives. 3. Determinations of acid dissociation constants of D-glucosamine and its three o-methyl derivatives. Chem. Pharm. Bull. 13, 330-332 (1965)

52. Domard, A.: Determination of $N$-acetyl content in chitosan samples by c. d. measurements. Int. J. Biol. Macromol. 9(6), 333-336 (1987)

53. Xu, J., Strandman, S., Zhu, J.X.X., Barralet, J., Cerruti, M.: Genipin-crosslinked catechol-chitosan mucoadhesive hydrogels for buccal drug delivery. Biomaterials 37, 395-404 (2015) 
54. Zeng, Z., Wang, H., Morsi, Y., Mo, X.: Synthesis and characterization of incorporating mussel mimetic moieties into photoactive hydrogel adhesive. Colloids Surf. B 161, 94-102 (2018)

55. Lee, D., Park, J.P., Koh, M.Y., Kim, P., Lee, J., Shin, M., Lee, H.: Chitosan-catechol: a writable bioink under serum culture media. Biomater. Sci. 6(5), 1040-1047 (2018)

56. Mikolasch, A., Hahn, V., Manda, K., Pump, J., Illas, N., Lalk, M., Salazar, G., Manuela, U.A.: Laccase-catalyzed cross-linking of amino acids and peptides with dihydroxylated aromatic compounds. Amino Acids 39(3), 671-683 (2010)

57. Garcia-Carmona, F., Garcia-Cánovas, F., Iborra, J.L., Lozano, J.A.: Kinetic study of the pathway of melanizationn between L-DOPA and dopachrome. BBA Gen. Sub. 717(1), 124-131 (1982)

58. Aktaş, N., Şahiner, N., Kantoğlu, Ö., Salih, B., Tanyolaç, A.: Biosynthesis and characterization of laccase catalyzed poly(catechol). J. Polym. Environ. 11(3), 123-128 (2003)

59. Lahtinen, M., Kruus, K., Heinonen, P., Sipil, J.: On the reactions of two fungal laceases differing in their redox potential with lignin model compounds: products and their rate of formation. J. Agric. Food Chem. 57(18), 8357-8365 (2009)

60. Roth, S., Spiess, A.C.: Laccases for biorefinery applications: a critical review on challenges and perspectives. Bioprocess Biosyst. Eng. 38(12), 2285-2313 (2015)

61. Lerner, A.B., Fitzpatrick, T.B.: Biochemistry of melanin formation. Physiol. Rev. 30(1), 91-126 (1950)

62. Mason, H.S., Peterson, E.W.: Melanoproteins I reactions between enzyme-generated quinones and amino acids. Biochim. Biophys. Acta 111(1), 134-146 (1965)

63. Qiu, W.Z., Wu, G.P., Xu, Z.K.: Robust coatings via catecholamine codeposition: mechanism, kinetics, and application. ACS Appl. Mater. Interfaces 10(6), 5902-5908 (2018)

64. Merritt, M.E., Christensen, A.M., Kramer, K.J., Hopkins, T.L., Schaefer, J.: Detection of intercatechol cross-links in insect cuticle by solid-state carbon-13 and nitrogen-15 NMR. J. Am. Chem. Soc. 118(45), 11278-11282 (1996)

65. Schaefer, J., Kramer, K.J., Garbow, J.R., Jacob, G.S., Stejskal, E.O., Hopkins, T.L., Speirs, R.D.: Aromatic cross-links in insect cuticle: detection by solid-state $13 \mathrm{C}$ and $15 \mathrm{~N}$ NMR. Science 235(4793), 1200-1204 (1987)

66. Kramer, K.J., Kanost, M.R., Hopkins, T.L., Jiang, H., Zhu, Y.C., $\mathrm{Xu}, \mathrm{R}$., Kerwin, J.L., Turecek, F.: Oxidative conjugation of catechols with proteins in insect skeletal systems. Tetrahedron 57(2), 385-392 (2001)
67. Xu, R., Huang, X., Hopkins, T.L., Kramer, K.J.: Catecholamine and histidyl protein cross-linked structures in sclerotized insect cuticle. Insect Biochem. Mol. Biol. 27(2), 101-108 (1997)

68. Peshkova, S., Li, K.: Investigation of chitosan-phenolics systems as wood adhesives. J. Biotechnol. 102(2), 199-207 (2003)

69. Michniewicz, A., Ullrich, R., Ledakowicz, S., Hofrichter, M.: The white-rot fungus Cerrena unicolor strain 137 produces two laccase isoforms with different physico-chemical and catalytic properties. Appl. Microbiol. Biotechnol. 69(6), 682-688 (2006)

70. Kirk, T.K., Schultz, E., Connors, W.J., Lorenz, L.F., Zeikus, J.G. Influence of culture parameters on lignin metabolism by Phanerochaete chrysosporium. Arch. Microbiol. 117(3), 277-285 (1978)

71. Herter, S., Schmidt, M., Thompson, M.L., Mikolasch, A., Schauer, F.: Study of enzymatic properties of phenol oxidase from nitrogen-fixing azotobacter chroococcum. AMB Express 1(1), 14 (2011)

72. Sondhi, S., Sharma, P., Saini, S., Puri, N., Gupta, N.: Purification and characterization of an extracellular, thermo-alkali-stable, metal tolerant laccase from Bacillus tequilensis SN4. PLoS ONE 9(5), e96951 (2014)

73. Linde, D.R., Weast, R.C.: CRC handbook of chemistry and physics. CRC Press, Boca Raton (1980)

74. Xu, R., Scarlett, B.: Particle Characterization: Light Scattering Methods, Particle Technology Series B. Springer, Dordrecht (2002)

75. Toteva, M.M., Richard, J.P.: The generation and reactions of quinone methides. Adv Phys Org Chem 45, 39-91 (2011)

76. Schwedt, G., Schmidt, T.C., Schmitz, O.J.: Analytische Chemie, 3rd edn. Wiley, Weinheim (2016)

77. Bellamy, L.J.: The Infra-red Spectra of Complex Molecules. Springer, Dordrecht (1975)

78. Narkar, A.R., Cannon, E., Yildirim-alicea, H., Ahn, K.: Catecholfunctionalized chitosan: optimized preparation method and its interaction with Mucin. Langmuir 35(48), 16013 (2019)

79. Ebnesajjad, S.: Handbook of Adhesives and Surface Preparation, 1st edn. Elsevier, Amsterdam (2011)

Publisher's Note Springer Nature remains neutral with regard to jurisdictional claims in published maps and institutional affiliations. 